\title{
The temperature structure of dusty planetary nebulae
}

\author{
G. Stasińska ${ }^{1}$ and R. Szczerba ${ }^{2}$ \\ 1 DAEC, Observatoire de Paris-Meudon, 92195 Meudon Cedex, France \\ e-mail: grazyna.stasinska@obspm.fr \\ 2 N. Copernicus Astronomical Center, Rabiańska 8, 87-100 Toruń, Poland \\ e-mail: szczerba@ncac.torun.pl
}

Received 19 July 2001 / Accepted 2 October 2001

\begin{abstract}
We have analyzed the effects of photoelectric heating by dust grains in photoionization models of planetary nebulae. We have shown that this process is particularly important if planetary nebulae contain a population of small grains. The presence of such grains would solve a number of problems that have found no satisfactory solution so far: i) the thermal energy deficit in some objects inferred from tailored photoionization modelling; ii) the large negative temperature gradients inferred directly from spatially resolved observations and indirectly from integrated spectra in some planetary nebulae; iii) the fact that the temperatures derived from the Balmer jump are smaller than those derived from [O III] $\lambda 4363 / 5007$; iv) the fact that the observed intensities of [O I] $\lambda 6300$ are often larger than predicted by photoionization models. In the presence of moderate density inhomogeneities, such as those inferred from high resolution images of planetary nebulae, photoelectric heating would boost the temperature of the tenuous component, which would then better confine the clumps. The temperature structure of such dusty and filamentary nebulae would solve the long-standing problem of temperature fluctuations posed by Peimbert (1967).
\end{abstract}

Key words. ISM: abundances - planetary nebulae: general - infrared: general - radiative transfer

\section{Introduction}

Infrared observations of planetary nebulae have established the presence of dust in these objects (see e.g. reviews by Barlow 1983; Roche 1989). Infrared spectra of planetary nebulae clearly show continuum emission in the midto far-infrared range due to dust thermal emission (see e.g. Pottasch et al. 1984). Superimposed on this continuum are dust features attributed to silicate dust particles (e.g. Aitken et al. 1979; Waters et al. 1998; Cohen et al. 1999) or carbon-based dust particles (e.g. Gillett et al. 1973; Waters et al. 1998; Cohen et al. 1999; Szczerba et al. 2001). The large depletion factors of refractory elements such as Fe, Mg and Si (Shields 1978; Péquignot \& Stasińska 1980; Shields 1983; Barlow 1993) and Ca (Aller \& Czyzak 1983; Volk et al. 1997) indicate that dust is intimately mixed with the ionized gas.

In a former paper (Stasińska \& Szczerba 1999), we performed a statistical analysis of a large sample of planetary nebulae with available IRAS photometric data by comparison with a grid of photoionization models for dusty planetary nebulae in which we computed the infra-red emission of dust heated by the absorbed stellar photons. The conclusion was that planetary nebulae contain dust in a

Send offprint requests to: G. Stasińska, e-mail: grazyna.stasinska@obspm.fr proportion from about $10^{-4}$ up to $10^{-2}$ by mass (adopting the canonical grain size distribution of Mathis et al. 1977 - hereafter the MRN distribution), and that there is no sign of an evolution of the dust content on a time scale of about $10^{4} \mathrm{yrs}$, contrary to earlier suggestions (Natta \& Panagia 1981; Pottasch 1984; Lenzuni et al. 1989).

That dust in ionized plasmas plays an important role in the thermal balance has been known since Spitzer (1948), who layed the foundation for a quantitative modelling of the effects of heating and cooling of dusty plasmas. Baldwin et al. (1991), Borkowski \& Harrington (1991), Binette et al. (1993), Viegas \& Contini (1994) and more recently Dopita \& Sutherland (2000) have included the effects of dust on the thermal balance of the gas in their photoionization codes. Of these, only the studies of Borkowski \& Harrington (1991) and Dopita \& Sutherland (2000) deal explicitly with planetary nebulae. Borkowski \& Harrington (1991) studied a very specific object, the galactic halo planetary nebula IRAS $18333-2357$ located in the globular cluster M 22, which is hydrogen-poor and extremely dusty. They showed that in this object, the heating of the nebular gas is essentially provided by the photoelectric emission from dust grains. Dopita \& Sutherland (2000) studied photoelectric heating by dust in normal planetary nebulae. They found its role to be important especially if one assumes the presence of small 
grains in a much higher proportion than inferred from the canonical MRN distribution.

In this paper, we develop further on the ideas of Dopita \& Sutherland (2000), addressing the temperature distribution inside planetary nebulae in more detail. This study is motivated by the fact that there are a number of unsolved problems relating to the temperature structure of planetary nebulae. The best known concerns the temperature fluctuations, whose existence has been postulated by Peimbert (1967) to explain the difference between the temperature $T_{\mathrm{r}[\mathrm{O} \text { III }]}$ derived from the $[\mathrm{O}$ III $] \lambda 4363 / 5007$ line ratio and the one derived from the Balmer jump. Using Peimbert's formulation, one derives a temperature fluctuation $t^{2}$ typically of 0.03-0.04 in planetary nebulae (Liu \& Danziger 1993, see also Esteban 2001 for a recent review). Although the Peimbert's approach relies on simplifications which are not necessarily justified (e.g. Kingdon \& Ferland 1995) and the real temperature variations may not be adequately described by his scheme (Stasińska 2001), the mere fact that the Balmer jump temperature is significantly lower than $T_{\mathrm{r}[\mathrm{O} I \mathrm{II}]}$ in a large number of planetary nebulae indicates that their temperature is far from uniform. While photoionization models do predict temperature gradients in planetary nebulae, as a result of the gradual modification of the ionizing radiation field and of the radial distributions of the ions responsible for the heating and the cooling of the gas, the computed gradient is too small to account for the difference between the Balmer jump temperature and $T_{\mathrm{r}[\mathrm{O} I \mathrm{II}]}$. Moderate density fluctuations are unable to produce temperature fluctuations on a $t^{2}=0.03$ level (Kingdon \& Ferland 1995). Very high density clumps $\left(n \sim 10^{6} \mathrm{~cm}^{-3}\right)$ can bias upwards the temperature derived from the [O III] $\lambda 4363 / 5007$ ratio due to collisional deexcitation of the [O III $] \lambda 5007$ line (Viegas \& Clegg 1994). However, the existence of such high densities in the $\mathrm{O}^{++}$emitting zone is not supported by the density sensitive line ratios observed in planetary nebulae both from the infrared fine structure [O III] lines and from the $[\mathrm{Ar} \mathrm{IV}] \lambda 4741 / 4713$ doublet (e.g. Liu et al. $2001 b)$. The magnitude of the temperature gradient observed in planetary nebulae either indirectly from a comparison of $T_{\mathrm{r}[\mathrm{OIII}]}$ with $T_{\mathrm{r}[\mathrm{NII}]}$, the temperature derived from $[\mathrm{N} \mathrm{II}] \lambda 5755 / 6584$ (see e.g. Kingsburgh \& Barlow 1994 or Peña et al. 2001) or directly from spatially resolved observations (Liu et al. 2000; Garnett \& Dinerstein 2001) is often difficult to account for by photoionization models.

In this paper, we explore whether photoionization models including the effects of dust on the thermal balance of the emitting gas can answer some of these questions.

In the next section, we briefly describe the photoionization code and dust properties. In Sect. 3, we study the temperature profiles of planetary nebulae with smooth density distributions. In Sect. 4, we discuss the temperature profiles of planetary nebulae with small scale density inhomogeneities. In Sect. 5, we discuss the effects of dust on methods of analysis of planetary nebulae based on emission line ratios. In Sect. 6 we discuss the temperature fluctuation parameter. Concluding remarks are given in Sect. 7.

\section{The building of dusty photoionization models}

\subsection{The treatment of dust in the photoionization code}

The present paper is based on results from the photoionization code PHOTO using the same atomic data as Stasińska \& Leitherer (1996). All the computations have been done under the assumption of spherical symmetry and adopting the outward only approximation for the diffuse ionizing radiation.

In the version of PHOTO used by Stasińska \& Szczerba (1999), we had adopted the formulation of Harrington et al. (1988) to compute the absorption of photons by dust grains, and their conversion into thermal radiation from the grains. For the present paper, we have also incorporated the effects of grains on the thermal balance of the gas, by implementing the physical processes between dust, gas and radiation relevant for dusty ionized regions as described in Appendix C of Baldwin et al. (1991) except that we do not consider an average grain size like former authors, but consider all the particle sizes explicitly. In short, the steady state grain potential is determined self-consistently for each dust particle size and the corresponding heating of the electron plasma by the photoelectric emission from dust is computed. As a check, the same treatment of dust has been applied to the photoionization code written by Szczerba (see e.g. Gessicki et al. 1996). Both codes give consistent results and reproduce the Baldwin et al. (1991) model for the Orion Nebula satisfactorily (their Fig. 16).

For simplicity, in this paper we consider only graphite grains (Draine \& Laor 1993) in our planetary nebulae models. We include two population of grains. One is composed of graphite grains with a bulk density of $2.5 \mathrm{~g} \mathrm{~cm}^{-3}$ and sizes distributed between 0.01 and $0.25 \mu \mathrm{m}$ according to the classical MRN model (hereafter referred to as standard grains). The second one consists of small grains, as introduced by Dopita \& Sutherland (2000). We assume that the small grain have a bulk density of $1 \mathrm{~g} \mathrm{~cm}^{-3}$ and that their sizes are distributed according to the same MRN law but between 0.001 and $0.01 \mu \mathrm{m}$. The formulae describing the photoelectron energy distribution and the yield are from Dopita \& Sutherland (2000). As explained by these authors, in comparison with the formulation of Baldwin et al. (1991) the adopted approach seems to be more realistic.

\subsection{The planetary nebula models}

We consider two families of photoionization models for planetary nebulae. The first one corresponds to a rather dense nebula ionized by a star that is not very hot. The reference model has a density $n(\mathrm{H})=10^{4} \mathrm{~cm}^{-3}$ and a stellar temperature $T_{*}=5 \times 10^{4} \mathrm{~K}$. The second one corresponds to a more diluted nebula ionized by a hotter star. We have 
Table 1. Definition of the models with $T_{*}=5 \times 10^{4} \mathrm{~K}$.

\begin{tabular}{lccccccc}
\hline model & Aa & Ba & Ca & Da & Ea & Fa & Ga \\
\hline$T_{*}[\mathrm{~K}]$ & $5 \times 10^{4}$ & $5 \times 10^{4}$ & $5 \times 10^{4}$ & $5 \times 10^{4}$ & $5 \times 10^{4}$ & $5 \times 10^{4}$ & $5 \times 10^{4}$ \\
$Q\left(\mathrm{H}^{0}\right)\left[\mathrm{ph} \mathrm{s}^{-1}\right]$ & $3 \times 10^{47}$ & $3 \times 10^{47}$ & $3 \times 10^{47}$ & $3 \times 10^{47}$ & $3 \times 10^{47}$ & $3 \times 10^{47}$ & $3 \times 10^{47}$ \\
$R_{\text {in }}[\mathrm{cm}]$ & $5 \times 10^{16}$ & $5 \times 10^{16}$ & $5 \times 10^{16}$ & $5 \times 10^{16}$ & $5 \times 10^{16}$ & $5 \times 10^{16}$ & $5 \times 10^{16}$ \\
$n(\mathrm{H})\left[\mathrm{cm}^{-3}\right]$ & $10^{4}$ & $10^{4}$ & $10^{4}$ & $10^{4}$ & Eq. (3) & Eq. (4) & Eq. (4) \\
dust properties no grains standard grains & standard + & standard + & no grains no grains & standard + \\
$m_{\mathrm{d}} / m_{\mathrm{H}}$ & 0 & $10^{-2}$ & $5 \times 10^{-3}+5 \times 10^{-3}$ & $5 \times 10^{-4}+5 \times 10^{-4}$ & 0 & 0 & $5 \times 10^{-3}+5 \times 10^{-3}$ \\
\hline
\end{tabular}

Table 2. Definition of the models with $T_{*}=10^{5} \mathrm{~K}$.

\begin{tabular}{lccccccc}
\hline model & $\mathrm{Ab}$ & $\mathrm{Bb}$ & $\mathrm{Cb}$ & $\mathrm{Db}$ & $\mathrm{Eb}$ & $\mathrm{Fb}$ & $\mathrm{Gb}$ \\
\hline$T_{*}[\mathrm{~K}]$ & $10^{5}$ & $10^{5}$ & $10^{5}$ & $10^{5}$ & $10^{5}$ & $10^{5}$ & $10^{5}$ \\
$Q\left(\mathrm{H}^{0}\right)\left[\mathrm{ph} \mathrm{s}^{-1}\right]$ & $3 \times 10^{47}$ & $3 \times 10^{47}$ & $3 \times 10^{47}$ & $3 \times 10^{47}$ & $3 \times 10^{47}$ & $3 \times 10^{47}$ & $3 \times 10^{47}$ \\
$R_{\text {in }}[\mathrm{cm}]$ & $8 \times 10^{16}$ & $8 \times 10^{16}$ & $8 \times 10^{16}$ & $8 \times 10^{16}$ & $8 \times 10^{16}$ & $8 \times 10^{16}$ & $8 \times 10^{16}$ \\
$n(\mathrm{H})\left[\mathrm{cm}^{-3}\right]$ & $5 \times 10^{3}$ & $5 \times 10^{3}$ & $5 \times 10^{3}$ & $5 \times 10^{3}$ & Eq. (3) & Eq. (4) & Eq. (4) \\
dust properties no grains standard grains & standard + & standard + & no grains no grains & standard + \\
$m_{\mathrm{d}} / m_{\mathrm{H}}$ & 0 & $10^{-2}$ & $5 \times 10^{-3}+5 \times 10^{-3}$ & $5 \times 10^{-4}+5 \times 10^{-4}$ & 0 & 0 & $5 \times 10^{-3}+5 \times 10^{-3}$ \\
\hline
\end{tabular}

chosen for the reference model $n(\mathrm{H})=5 \times 10^{3} \mathrm{~cm}^{-3}$ and $T_{*}=10^{5} \mathrm{~K}$. The stars are assumed to radiate as blackbodies. The inner radius of the nebula is chosen to be $5 \times 10^{16} \mathrm{~cm}$ for the former case, and $8 \times 10^{16} \mathrm{~cm}$ for the latter one. In both cases, we assume that the total number of $\mathrm{H}$ Lyman continuum photons emitted by the star, $Q\left(\mathrm{H}^{0}\right)$ is equal to $3 \times 10^{47} \mathrm{ph} \mathrm{s}^{-1}$ and that the nebulae are ionization bounded (the calculations are stopped when the proportion of neutral hydrogen exceeds 0.03). This implies that the total nebular mass is larger than $\simeq 0.1 M_{\odot}$ for the first case, and larger than $\simeq 0.3 M_{\odot}$ for the second case, which are reasonable values. Actually, the local properties of our models do not depend on whether the nebula is ionization- or density-bounded, but the integrated properties do depend on that, since the low excitation parts are suppressed for density-bounded nebulae. In Tables 1 and 2 we have collected the key parameters used in the models computed by us for $T_{*}=5 \times 10^{4} \mathrm{~K}$ and $10^{5} \mathrm{~K}$, respectively. These tables allow to easily relate the name of the model to the physical parameters adopted in that model.

Our models have the following chemical composition: $\mathrm{He} / \mathrm{H}=0.115 ; \mathrm{C} / \mathrm{H}=5.50 \times 10^{-4} ; \mathrm{N} / \mathrm{H}=2.24 \times 10^{-4}$; $\mathrm{O} / \mathrm{H}=4.79 \times 10^{-4} ; \mathrm{Ne} / \mathrm{H}=1.23 \times 10^{-4} ; \mathrm{Mg} / \mathrm{H}=$ $3.80 \times 10^{-5} ; \mathrm{Si} / \mathrm{H}=3.55 \times 10^{-5} ; \mathrm{S} / \mathrm{H}=8.32 \times 10^{-6}$; $\mathrm{Cl} / \mathrm{H}=1.86 \times 10^{-7} ; \mathrm{Ar} / \mathrm{H}=2.46 \times 10^{-6} ; \mathrm{Fe} / \mathrm{H}=$ $4.68 \times 10^{-5}$, which corresponds to the average chemical composition of the Galactic planetary nebulae from the Kingsburgh \& Barlow (1994) sample (Mg, Si, Cl and Fe have solar abundances). This chemical composition is assumed throughout or study, regardless of the dust abundance. The reason for adopting such a policy is its simplicity. Of course, if metallic or carbon atoms are condensed into grains, their gas phase abundances are correspondingly depleted. However, such elements as $\mathrm{Si}, \mathrm{Mg}, \mathrm{Fe}$ do not play a dominant role in the energy balance. Carbon, on the other hand, can play an important role, especially in carbon-rich planetary nebulae. However, we are not interested here to investigate what would happen to a planetary nebula of given chemical composition if part of its carbon content were locked into grains. We rather wish to explore what are the effects of dust on the temperature structure of planetary nebulae.

In Tables 3 and 4 we summarize some interesting features of the models discussed in this paper. We list the total $\mathrm{H} \beta$ fluxes in erg $\mathrm{cm}^{-2} \mathrm{~s}^{-1}$ and the fluxes in the four IRAS bands at 12, 25, 60 and $100 \mu \mathrm{m}$, assuming that the nebulae lie at a distance of $1 \mathrm{kpc}$. Below we give the intensities relative to $\mathrm{H} \beta$ of helium and oxygen lines. These are sufficient to give a fair understanding of the behaviour of the emission line spectra. We also list the intensities of the most important lines of $\mathrm{C}, \mathrm{N}$ and $\mathrm{Ne}$ used in abundance determinations. We do not compute the reddening by internal dust, so that the listed line intensities are relevant to observations corrected for reddening (the dereddening procedure, ideally consisting of fitting the observed Balmer decrement to the theoretical one, actually produces a small error in the ratios of lines arising from different ions). Then we list the two temperature, sensitive line ratios [O III $] \lambda 4363 / 5007$ and [N II] $\lambda 5755 / 6584$, and the 
Table 3. Selected properties for models with $T_{*}=5 \times 10^{4} \mathrm{~K}$.

\begin{tabular}{|c|c|c|c|c|c|c|c|}
\hline & model Aa & model $\mathrm{Ba}$ & model $\mathrm{Ca}$ & model Da & model Ea & model Fa & model Ga \\
\hline$F(\mathrm{H} \beta)$ & 1.149E-09 & $8.082 \mathrm{E}-10$ & $1.774 \mathrm{E}-10$ & $7.250 \mathrm{E}-10$ & 1.137E-09 & 1.145E-09 & $2.202 \mathrm{E}-10$ \\
\hline$F_{12}^{\mathrm{IRAS}}$ & $6.175 \mathrm{E}+00$ & $2.819 \mathrm{E}+01$ & $1.420 \mathrm{E}+02$ & $5.914 \mathrm{E}+01$ & $5.155 \mathrm{E}+00$ & $5.342 \mathrm{E}+00$ & $1.400 \mathrm{E}+02$ \\
\hline$F_{25}^{\mathrm{IRAS}}$ & $5.667 \mathrm{E}+00$ & $3.885 \mathrm{E}+02$ & $6.182 \mathrm{E}+02$ & $2.484 \mathrm{E}+02$ & $4.572 \mathrm{E}+00$ & $4.603 \mathrm{E}+00$ & $5.926 \mathrm{E}+02$ \\
\hline$F_{60}^{\operatorname{IRAS}}$ & $1.473 \mathrm{E}+01$ & $3.865 \mathrm{E}+02$ & $3.445 \mathrm{E}+02$ & $1.376 \mathrm{E}+02$ & $1.048 \mathrm{E}+01$ & $1.007 \mathrm{E}+01$ & $3.154 \mathrm{E}+02$ \\
\hline$F_{100}^{\mathrm{IRAS}}$ & $3.302 \mathrm{E}+00$ & $7.361 \mathrm{E}+01$ & $5.499 \mathrm{E}+01$ & $2.173 \mathrm{E}+01$ & $2.200 \mathrm{E}+00$ & $2.290 \mathrm{E}+00$ & $4.912 \mathrm{E}+01$ \\
\hline Не г $\lambda 5876$ & $1.680 \mathrm{E}-01$ & $1.711 \mathrm{E}-01$ & $1.890 \mathrm{E}-01$ & $1.745 \mathrm{E}-01$ & $1.693 \mathrm{E}-01$ & $1.689 \mathrm{E}-01$ & $1.882 \mathrm{E}-01$ \\
\hline Не II $\lambda 4686$ & $1.728 \mathrm{E}-03$ & $2.405 \mathrm{E}-03$ & $8.745 \mathrm{E}-03$ & $2.556 \mathrm{E}-03$ & $1.763 \mathrm{E}-03$ & $1.730 \mathrm{E}-03$ & 7.367E-03 \\
\hline$[\mathrm{O}$ I $] \lambda 6300$ & $6.771 \mathrm{E}-03$ & $8.911 \mathrm{E}-03$ & $6.110 \mathrm{E}-02$ & $1.615 \mathrm{E}-02$ & $2.651 \mathrm{E}-03$ & $1.350 \mathrm{E}-02$ & $7.165 \mathrm{E}-02$ \\
\hline$[\mathrm{O}$ II $] \lambda 3726,3729$ & $5.428 \mathrm{E}-01$ & $6.018 \mathrm{E}-01$ & $1.466 \mathrm{E}+00$ & $7.069 \mathrm{E}-01$ & $4.573 \mathrm{E}-01$ & 4.612E-01 & $1.187 \mathrm{E}+00$ \\
\hline$[\mathrm{O}$ II $] \lambda 7320,7330$ & $6.371 \mathrm{E}-02$ & $7.428 \mathrm{E}-02$ & $2.564 \mathrm{E}-01$ & $9.629 \mathrm{E}-02$ & $6.211 \mathrm{E}-02$ & $1.053 \mathrm{E}-01$ & $3.362 \mathrm{E}-01$ \\
\hline O II $\lambda 4651$ & 4.101E-03 & $4.165 \mathrm{E}-03$ & $4.302 \mathrm{E}-03$ & $4.396 \mathrm{E}-03$ & $4.450 \mathrm{E}-03$ & $3.649 \mathrm{E}-03$ & $3.779 \mathrm{E}-03$ \\
\hline O III] $\lambda 1663$ & $9.149 \mathrm{E}-03$ & $1.385 \mathrm{E}-02$ & $6.448 \mathrm{E}-01$ & $3.619 \mathrm{E}-02$ & $1.134 \mathrm{E}-02$ & $9.393 \mathrm{E}-03$ & $4.560 \mathrm{E}-01$ \\
\hline$[\mathrm{O}$ III $] \lambda 4363$ & $1.530 \mathrm{E}-02$ & $2.067 \mathrm{E}-02$ & $2.942 \mathrm{E}-01$ & 4.051E-02 & $1.870 \mathrm{E}-02$ & $1.553 \mathrm{E}-02$ & $2.148 \mathrm{E}-01$ \\
\hline$[\mathrm{O}$ III $] \lambda 5007$ & $4.627 \mathrm{E}+00$ & $5.410 \mathrm{E}+00$ & $1.882 \mathrm{E}+01$ & $7.625 \mathrm{E}+00$ & $5.217 \mathrm{E}+00$ & $4.264 \mathrm{E}+00$ & $1.461 \mathrm{E}+01$ \\
\hline [O III $] \lambda 52 \mu \mathrm{m}$ & $3.486 \mathrm{E}-01$ & $3.650 \mathrm{E}-01$ & $5.100 \mathrm{E}-01$ & 4.107E-01 & $2.502 \mathrm{E}-01$ & $2.380 \mathrm{E}-01$ & $3.276 \mathrm{E}-01$ \\
\hline [O III $] \lambda 88 \mu \mathrm{m}$ & 4.392E-02 & 4.603E-02 & $6.481 \mathrm{E}-02$ & $5.189 \mathrm{E}-02$ & $2.936 \mathrm{E}-02$ & $3.058 \mathrm{E}-02$ & $4.259 \mathrm{E}-02$ \\
\hline C III] $\lambda 1909$ & $3.095 \mathrm{E}-01$ & $4.357 \mathrm{E}-01$ & $9.567 \mathrm{E}+00$ & $9.298 \mathrm{E}-01$ & $3.663 \mathrm{E}-01$ & $3.244 \mathrm{E}-01$ & $6.858 \mathrm{E}+00$ \\
\hline$[\mathrm{N}$ II] $\lambda 6584$ & $1.334 \mathrm{E}+00$ & $1.391 \mathrm{E}+00$ & $2.514 \mathrm{E}+00$ & $1.466 \mathrm{E}+00$ & $1.071 \mathrm{E}+00$ & $1.589 \mathrm{E}+00$ & $2.790 \mathrm{E}+00$ \\
\hline$[\mathrm{Ne}$ III $] \lambda 3869$ & $3.679 \mathrm{E}-01$ & $4.486 \mathrm{E}-01$ & $2.119 \mathrm{E}+00$ & $6.829 \mathrm{E}-01$ & $4.192 \mathrm{E}-01$ & $3.584 \mathrm{E}-01$ & $1.689 \mathrm{E}+00$ \\
\hline [O III $] \lambda 4363 / 5007$ & $3.308 \mathrm{E}-03$ & $3.822 \mathrm{E}-03$ & $1.564 \mathrm{E}-02$ & $5.313 \mathrm{E}-03$ & $3.585 \mathrm{E}-03$ & $3.643 \mathrm{E}-03$ & $1.470 \mathrm{E}-02$ \\
\hline$[\mathrm{N}$ II $] \lambda 5755 / 6584$ & $1.132 \mathrm{E}-02$ & $1.215 \mathrm{E}-02$ & $1.940 \mathrm{E}-02$ & $1.407 \mathrm{E}-02$ & $1.248 \mathrm{E}-02$ & $1.752 \mathrm{E}-02$ & $2.535 \mathrm{E}-02$ \\
\hline$(F \lambda 3642-F \lambda 3648) / F(\mathrm{H} \beta)$ & 4.902E-03 & $4.801 \mathrm{E}-03$ & $4.026 \mathrm{E}-03$ & $4.593 \mathrm{E}-03$ & $4.852 \mathrm{E}-03$ & $4.855 \mathrm{E}-03$ & $4.132 \mathrm{E}-03$ \\
\hline$[\mathrm{S}$ II $] \lambda 6731 / 6717$ & $1.991 \mathrm{E}+00$ & $1.980 \mathrm{E}+00$ & $1.860 \mathrm{E}+00$ & $1.924 \mathrm{E}+00$ & $1.896 \mathrm{E}+00$ & $2.097 \mathrm{E}+00$ & $1.986 \mathrm{E}+00$ \\
\hline$[\mathrm{Ar}$ IV] $\lambda 4741 / 4713$ & $1.691 \mathrm{E}+00$ & $1.673 \mathrm{E}+00$ & $1.500 \mathrm{E}+00$ & $1.629 \mathrm{E}+00$ & $2.340 \mathrm{E}+00$ & $1.885 \mathrm{E}+00$ & $1.598 \mathrm{E}+00$ \\
\hline$T_{0}\left(\mathrm{H}^{+}\right)$ & 8151. & 8427 & 11807. & 9070. & 8279. & 8268. & 11208. \\
\hline$T_{0}\left(\mathrm{O}^{+}\right)$ & 7972. & 8184. & 10010. & 8672. & 8116. & 8162. & 9870. \\
\hline$T_{0}\left(\mathrm{O}^{++}\right)$ & 8232. & 8529. & 12360. & 9204. & 8334. & 8335. & 11836. \\
\hline$t^{2}\left(\mathrm{H}^{+}\right)$ & $8.0 \mathrm{E}-4$ & $1.3 \mathrm{E}-3$ & $4.6 \mathrm{E}-2$ & $4.5 \mathrm{E}-3$ & $7.0 \mathrm{E}-4$ & $6.6 \mathrm{E}-4$ & $4.4 \mathrm{E}-2$ \\
\hline$t^{2}\left(\mathrm{O}^{+}\right)$ & $1.3 \mathrm{E}-3$ & $1.6 \mathrm{E}-3$ & $1.2 \mathrm{E}-2$ & $1.9 \mathrm{E}-3$ & $1.6 \mathrm{E}-4$ & $7.7 \mathrm{E}-4$ & $7.3 \mathrm{E}-3$ \\
\hline$t^{2}\left(\mathrm{O}^{++}\right)$ & $2.9 \mathrm{E}-4$ & $6.7 \mathrm{E}-4$ & 4.3E-2 & $4.4 \mathrm{E}-3$ & $2.4 \mathrm{E}-4$ & $4.3 \mathrm{E}-4$ & $4.6 \mathrm{E}-2$ \\
\hline
\end{tabular}

Balmer jump defined as $(F \lambda 3642-F \lambda 3648) / F(\mathrm{H} \beta)$, where $F \lambda 3642$ and $F \lambda 3648$ are the nebular continuum fluxes at 3642 and $3648 \AA$. Below are given the two density-sensitive line ratios $[\mathrm{S} \mathrm{II}] \lambda 6731 / 6717$ and $[\mathrm{Ar}$ IV] $\lambda 4741 / 4713$.

Next we give the values of the average ionic temperatures $T_{0}\left(\mathrm{H}^{+}\right), T_{0}\left(\mathrm{O}^{+}\right)$and $T_{0}\left(\mathrm{O}^{++}\right)$, where $T_{0}\left(\mathrm{X}^{+j}\right)$ is defined as:

$T_{0}\left(\mathrm{X}^{+j}\right)=\frac{\int T_{\mathrm{e}} n\left(\mathrm{X}^{+j}\right) n_{\mathrm{e}} \mathrm{d} V}{\int n\left(\mathrm{X}^{+j}\right) n_{\mathrm{e}} \mathrm{d} V}$,

and $T_{\mathrm{e}}$ is the local electron temperature, $n_{\mathrm{e}}$ the electron density, $n\left(\mathrm{X}^{+j}\right)$ stands for the ion concentration, the integration being performed over the total volume.

The last three lines give the values of $t^{2}\left(\mathrm{H}^{+}\right), t^{2}\left(\mathrm{O}^{+}\right)$ and $t^{2}\left(\mathrm{O}^{++}\right)$, where $t^{2}\left(\mathrm{X}^{+j}\right)$ is defined as:

$t^{2}\left(\mathrm{X}^{+j}\right)=\frac{\int\left(T_{\mathrm{e}}-T_{0}\left(\mathrm{X}^{+j}\right)\right)^{2} n\left(\mathrm{X}^{+j}\right) n_{\mathrm{e}} \mathrm{d} V}{T_{0}\left(\mathrm{X}^{+j}\right)^{2} \int n\left(\mathrm{X}^{+j}\right) n_{\mathrm{e}} \mathrm{d} V}$.

\section{The effect of dust on the temperature profiles of planetary nebulae with smooth density distributions}

We first investigate the simplest case of a uniform density distribution. Figure 1 shows the results of dust-free models (Models Aa and $\mathrm{Ab}$ ) for the $n(\mathrm{H})=10^{4} \mathrm{~cm}^{-3}, T_{*}=5 \times$ $10^{4} \mathrm{~K}$ case (upper panels) and for the $n(\mathrm{H})=5 \times 10^{3} \mathrm{~cm}^{-3}$, $T_{*}=10^{5} \mathrm{~K}$ case (lower panels). The left panels show the electron temperature (thick line) and hydrogen number density (thin line) as a function of the distance $R$ to the star. The right panels show the ionization fraction of $\mathrm{He}^{+}$ (thick line) and $\mathrm{O}^{++}$(thin line).

In Fig. 2, we display with the same conventions the results of dusty models ( $\mathrm{Ba}$ and $\mathrm{Bb}$ ) in which dust is composed of graphite grains with the MRN size distribution between 0.01 and $0.25 \mu \mathrm{m}$ and a dust-to-hydrogen mass 
Table 4. Selected properties of models with $T_{*}=10^{5} \mathrm{~K}$.

\begin{tabular}{|c|c|c|c|c|c|c|c|}
\hline & model $\mathrm{Ab}$ & model Bb & model $\mathrm{Cb}$ & model Db & model Eb & model $\mathrm{Fb}$ & model Gb \\
\hline$F(\mathrm{H} \beta)$ & $1.185 \mathrm{E}-09$ & 8.961E-10 & $3.204 \mathrm{E}-10$ & $8.930 \mathrm{E}-10$ & $1.163 \mathrm{E}-09$ & 1.169E-09 & $2.939 \mathrm{E}-10$ \\
\hline$F_{12}^{\mathrm{IRAS}}$ & $1.064 \mathrm{E}+01$ & $1.162 \mathrm{E}+01$ & $4.887 \mathrm{E}+01$ & $2.260 \mathrm{E}+01$ & $1.057 \mathrm{E}+01$ & $8.337 \mathrm{E}+00$ & $8.595 \mathrm{E}+01$ \\
\hline$F_{25}^{\mathrm{IRAS}}$ & $1.879 \mathrm{E}+01$ & $2.224 \mathrm{E}+02$ & $5.616 \mathrm{E}+02$ & $1.917 \mathrm{E}+02$ & $1.193 \mathrm{E}+01$ & $1.524 \mathrm{E}+01$ & $5.785 \mathrm{E}+02$ \\
\hline$F_{60}^{\mathrm{IRAS}}$ & $3.721 \mathrm{E}+01$ & $4.668 \mathrm{E}+02$ & $5.697 \mathrm{E}+02$ & $1.936 \mathrm{E}+02$ & $3.154 \mathrm{E}+01$ & $2.452 \mathrm{E}+01$ & $4.604 \mathrm{E}+02$ \\
\hline$F_{100}^{\mathrm{IRAS}}$ & $1.061 \mathrm{E}+01$ & $1.199 \mathrm{E}+02$ & $1.185 \mathrm{E}+02$ & $4.045 \mathrm{E}+01$ & $8.651 \mathrm{E}+00$ & $6.967 \mathrm{E}+00$ & $8.842 \mathrm{E}+01$ \\
\hline Не г $\lambda 5876$ & $1.636 \mathrm{E}-01$ & $1.606 \mathrm{E}-01$ & $1.432 \mathrm{E}-01$ & $1.616 \mathrm{E}-01$ & $1.635 \mathrm{E}-01$ & $1.672 \mathrm{E}-01$ & $1.471 \mathrm{E}-01$ \\
\hline Не II $\lambda 4686$ & $1.082 \mathrm{E}-01$ & $1.362 \mathrm{E}-01$ & $3.212 \mathrm{E}-01$ & $1.385 \mathrm{E}-01$ & $1.123 \mathrm{E}-01$ & $1.109 \mathrm{E}-01$ & $3.363 \mathrm{E}-01$ \\
\hline$[\mathrm{O}$ I $] \lambda 6300$ & $5.159 \mathrm{E}-02$ & $5.559 \mathrm{E}-02$ & $1.044 \mathrm{E}-01$ & $6.262 \mathrm{E}-02$ & $2.313 \mathrm{E}-02$ & $7.552 \mathrm{E}-02$ & $1.615 \mathrm{E}-01$ \\
\hline$[\mathrm{O}$ II] $\lambda 3726,3729$ & $1.110 \mathrm{E}+00$ & $1.189 \mathrm{E}+00$ & $1.982 \mathrm{E}+00$ & $1.306 \mathrm{E}+00$ & $8.950 \mathrm{E}-01$ & $1.022 \mathrm{E}+00$ & $1.757 \mathrm{E}+00$ \\
\hline$[\mathrm{O} \mathrm{II]} \lambda 7320,7330$ & $1.086 \mathrm{E}-01$ & $1.153 \mathrm{E}-01$ & $2.083 \mathrm{E}-01$ & $1.315 \mathrm{E}-01$ & $7.963 \mathrm{E}-02$ & $1.821 \mathrm{E}-01$ & $3.282 \mathrm{E}-01$ \\
\hline О Іі $\lambda 4651$ & $4.830 \mathrm{E}-03$ & $4.670 \mathrm{E}-03$ & $3.905 \mathrm{E}-03$ & $4.677 \mathrm{E}-03$ & $5.192 \mathrm{E}-03$ & $4.557 \mathrm{E}-03$ & $3.638 \mathrm{E}-03$ \\
\hline O III] $\lambda 1663$ & $1.059 \mathrm{E}-01$ & $1.206 \mathrm{E}-01$ & $4.862 \mathrm{E}-01$ & $1.638 \mathrm{E}-01$ & $1.365 \mathrm{E}-01$ & $1.043 \mathrm{E}-01$ & $4.718 \mathrm{E}-01$ \\
\hline [O III $] \lambda 4363$ & $9.251 \mathrm{E}-02$ & $1.005 \mathrm{E}-01$ & $2.578 \mathrm{E}-01$ & $1.262 \mathrm{E}-01$ & $1.144 \mathrm{E}-01$ & $9.109 \mathrm{E}-02$ & $2.475 \mathrm{E}-01$ \\
\hline [O III $] \lambda 5007$ & $1.255 \mathrm{E}+01$ & $1.284 \mathrm{E}+01$ & $1.859 \mathrm{E}+01$ & $1.445 \mathrm{E}+01$ & $1.439 \mathrm{E}+01$ & $1.189 \mathrm{E}+01$ & $1.727 \mathrm{E}+01$ \\
\hline [O III $] \lambda 52 \mu \mathrm{m}$ & 8.893E-01 & 8.716E-01 & $8.428 \mathrm{E}-01$ & $9.008 \mathrm{E}-01$ & 7.739E-01 & $5.950 \mathrm{E}-01$ & $5.527 \mathrm{E}-01$ \\
\hline$[\mathrm{O}$ III $] \lambda 88 \mu \mathrm{m}$ & $1.379 \mathrm{E}-01$ & $1.353 \mathrm{E}-01$ & $1.321 \mathrm{E}-01$ & $1.403 \mathrm{E}-01$ & $1.143 \mathrm{E}-01$ & $9.172 \mathrm{E}-02$ & 8.593E-02 \\
\hline C III] $\lambda 1909$ & $2.093 \mathrm{E}+00$ & $2.289 \mathrm{E}+00$ & $6.975 \mathrm{E}+00$ & $2.931 \mathrm{E}+00$ & $2.579 \mathrm{E}+00$ & $2.095 \mathrm{E}+00$ & $6.675 \mathrm{E}+00$ \\
\hline$[\mathrm{N}$ II] $\lambda 6584$ & $1.829 \mathrm{E}+00$ & $1.955 \mathrm{E}+00$ & $3.042 \mathrm{E}+00$ & $2.086 \mathrm{E}+00$ & $1.217 \mathrm{E}+00$ & $2.272 \mathrm{E}+00$ & $3.632 \mathrm{E}+00$ \\
\hline [Ne III] $\lambda 3869$ & $1.341 \mathrm{E}+00$ & $1.403 \mathrm{E}+00$ & $2.355 \mathrm{E}+00$ & $1.609 \mathrm{E}+00$ & $1.482 \mathrm{E}+00$ & $1.353 \mathrm{E}+00$ & $2.307 \mathrm{E}+00$ \\
\hline [O III] $\lambda 4363 / 5007$ & $7.374 \mathrm{E}-03$ & $7.828 \mathrm{E}-03$ & $1.387 \mathrm{E}-02$ & $8.729 \mathrm{E}-03$ & $7.948 \mathrm{E}-03$ & $7.660 \mathrm{E}-03$ & $1.433 \mathrm{E}-02$ \\
\hline$[\mathrm{N}$ II $] \lambda 5755 / 6584$ & $1.688 \mathrm{E}-02$ & $1.668 \mathrm{E}-02$ & $1.877 \mathrm{E}-02$ & $1.764 \mathrm{E}-02$ & $1.826 \mathrm{E}-02$ & $2.123 \mathrm{E}-02$ & $2.311 \mathrm{E}-02$ \\
\hline$(F \lambda 3642-F \lambda 3648) / F(\mathrm{H} \beta)$ & $4.279 \mathrm{E}-03$ & $4.256 \mathrm{E}-03$ & $3.965 \mathrm{E}-03$ & $4.165 \mathrm{E}-03$ & $4.228 \mathrm{E}-03$ & $4.269 \mathrm{E}-03$ & $3.979 \mathrm{E}-03$ \\
\hline [S II] $\lambda 6731 / 6717$ & $1.690 \mathrm{E}+00$ & $1.689 \mathrm{E}+00$ & $1.674 \mathrm{E}+00$ & $1.685 \mathrm{E}+00$ & $1.446 \mathrm{E}+00$ & $1.809 \mathrm{E}+00$ & $1.828 \mathrm{E}+00$ \\
\hline$[$ Ar IV] $\lambda 4741 / 4713$ & $1.183 \mathrm{E}+00$ & $1.179 \mathrm{E}+00$ & $1.147 \mathrm{E}+00$ & $1.172 \mathrm{E}+00$ & $1.430 \mathrm{E}+00$ & $1.435 \mathrm{E}+00$ & $1.406 \mathrm{E}+00$ \\
\hline$T_{0}\left(\mathrm{H}^{+}\right)$ & 10410. & 10602. & 12906. & 10988. & 10615. & 10462. & 13120. \\
\hline$T_{0}\left(\mathrm{O}^{+}\right)$ & 10097. & 10045. & 10575 & 10312. & 10566. & 10164. & 10661. \\
\hline$T_{0}\left(\mathrm{O}^{++}\right)$ & 10310. & 10489. & 12576. & 10874. & 10523. & 10347. & 12597. \\
\hline$t^{2}\left(\mathrm{H}^{+}\right)$ & $4.9 \mathrm{E}-3$ & $6.7 \mathrm{E}-3$ & $3.4 \mathrm{E}-2$ & 7.3E-3 & $3.7 \mathrm{E}-3$ & $5.9 \mathrm{E}-3$ & $6.5 \mathrm{E}-2$ \\
\hline$t^{2}\left(\mathrm{O}^{+}\right)$ & $2.4 \mathrm{E}-3$ & $2.9 \mathrm{E}-3$ & $8.1 \mathrm{E}-3$ & $3.2 \mathrm{E}-3$ & $2.7 \mathrm{E}-3$ & $1.3 \mathrm{E}-3$ & $7.0 \mathrm{E}-3$ \\
\hline$t^{2}\left(\mathrm{O}^{++}\right)$ & $2.1 \mathrm{E}-3$ & $2.6 \mathrm{E}-3$ & $1.4 \mathrm{E}-2$ & $2.7 \mathrm{E}-3$ & $2.4 \mathrm{E}-3$ & $2.6 \mathrm{E}-3$ & $1.6 \mathrm{E}-2$ \\
\hline
\end{tabular}

ratio, $m_{\mathrm{d}} / m_{\mathrm{H}}$, of $10^{-2}$. Clearly, the size of the ionized zone is shrunken with respect to the dust-free models shown in Fig. 1, because with such $m_{\mathrm{d}} / m_{\mathrm{H}}$ the grains significantly compete with gas for the absorption of the Lyman continuum photons. However, there is no strong effect either on the temperature structure of the nebula or on the ratios of emission lines with respect to $\mathrm{H} \beta$, as can be seen in Tables 3 and 4 . The only notable difference is in the $\mathrm{H} \beta$ and the IRAS fluxes. The $\mathrm{H} \beta$ flux is reduced in the dusty models by about $30 \%$, while the fluxes in the IRAS bands are increased by large amounts due to the thermal emission of the dust grains that have been heated by the stellar and nebular photons (note that in the dust-free models, the fluxes in the IRAS bands are not zero due to the contribution of the fine structure lines from atomic ions).
Figure 3 shows models $\mathrm{Ca}$ and $\mathrm{Cb}$ which differ from models $\mathrm{Ba}$ and $\mathrm{Bb}$ only in that half of the dust mass is now in small grains of size from 0.001 to $0.01 \mu \mathrm{m}$. That is to say, large grains and small grains coexist, with a dust-to-hydrogen mass ratio of $5 \times 10^{-3}$ for each component. Now, the $\mathrm{H} \beta$ fluxes are considerably reduced, by a factor 4 in the $T_{*}=10^{5} \mathrm{~K}$ model and by a factor 6 in the $T_{*}=5 \times 10^{4} \mathrm{~K}$ one, with respect to the dust-free models. Indeed, the mass absorption efficiency of small graphite grains is much larger than that of large ones (see Draine \& Laor 1993). In addition, small grains are heated to higher temperatures, because the heating of grains is proportional to their surface while the cooling is proportional to their volume. This translates into much larger fluxes in the $12 \mu \mathrm{m}$ band (by a factor of about 4) and in the $25 \mu \mathrm{m}$ band (by a factor of about 2) when comparing 

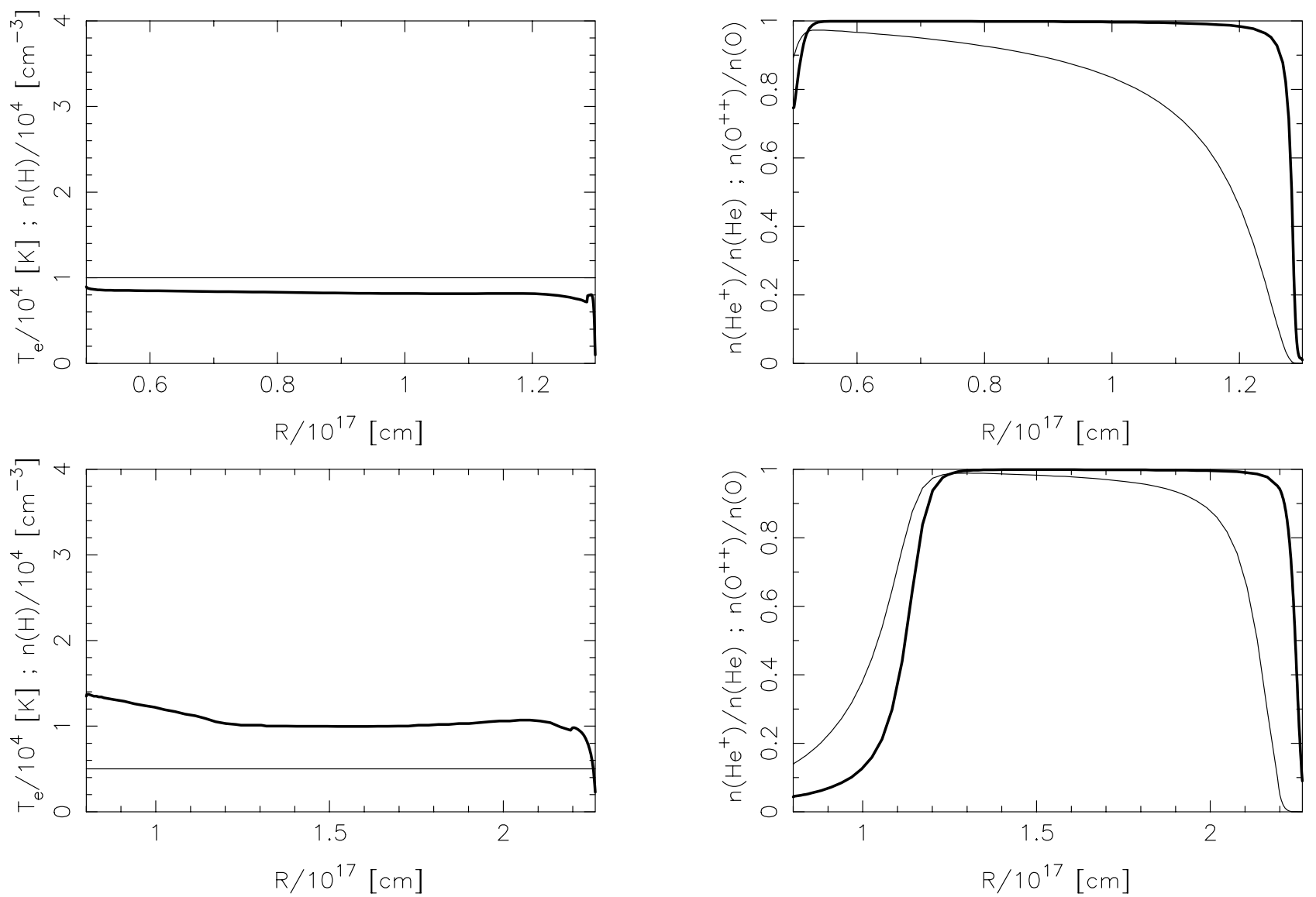

Fig. 1. The temperature and ionization structure of dust-free and constant density model planetary nebulae (Models Aa and Ab). Upper panels: models with $n(\mathrm{H})=10^{4} \mathrm{~cm}^{-3}$ and $T_{*}=5 \times 10^{4} \mathrm{~K}$. Lower panels, models with $n(\mathrm{H})=5 \times 10^{3} \mathrm{~cm}-3$ and $T_{*}=10^{5} \mathrm{~K}$. Left: electron temperature (thick line) and hydrogen concentration (thin line) as a function of the distance to the star; right: ionization fraction of $\mathrm{He}^{+}$(thick line) and $\mathrm{O}^{++}$(thin line). Note that here as well as in the other figures of the paper, the horizontal scale matches the size of the ionized region and is therefore different for each model, while the vertical scale is always the same.

with models computed solely with the MRN dust, as seen in Tables 3 and 4 .

What is striking from the comparison of Fig. 3 with Figs. 1 and 2 is the very significant increase in the gas temperature when a population of small grains is included. Figure 4 shows the contribution of the gas heating due to the photoelectric effect with respect to the total heating (thick line) and the ratio between gas cooling due to grain-gas collisions and the total cooling (thin line) as a function of the distance to the central star. As expected, the contribution of photoelectric heating is largest close to the star. Indeed, the heating due to photoelectrons from dust grains per unit volume of gas, $\Gamma_{\mathrm{d}}$, is proportional to the number density of dust grains and to the intensity of the stellar radiation field. The heating due to photoionization of hydrogen, $\Gamma_{\mathrm{H}}$, is proportional to the number density of neutral hydrogen and to the stellar radiation field. Using the ionization equilibrium equation for hydrogen, one then finds that $\Gamma_{\mathrm{H}}$ is simply proportional to the square of the gas density. It follows that the ratio $\Gamma_{\mathrm{d}} / \Gamma_{\mathrm{H}}$ is simply proportional to $\left(m_{\mathrm{d}} / m_{\mathrm{H}}\right) U$, where $U$ is the local ionization parameter, defined as $Q\left(\mathrm{H}^{0}\right) /\left(4 \pi R^{2} n_{\mathrm{e}} c\right)(c$ is the speed of light). Therefore, the photoelectric effect becomes insignificant in fully ionized plasma at large distances from the central stars. This results in an important electron temperature gradient, which was also seen in the models of Dopita \& Sutherland (2000). Consequently, [O III $] \lambda 4363 / 5007$ is increased, and the intensities of collisionally excited lines such as $[\mathrm{O}$ III $] \lambda 5007,[\mathrm{O}$ III $] \lambda 4363$ or O III] $\lambda 1663$ are increased with respect to $\mathrm{H} \beta$, as seen in Tables 3 and 4 . As already noted by previous workers (see Baldwin et al. 1991) cooling due to gas-grain collisions can also be important in the energy budget of the gas, and the net effect of the grains on the gas temperature is not necessarily positive. In the models shown in Fig. 4, the net effect is slightly negative in the $\mathrm{O}^{+}$zone.

Another noteworthy effect of the presence of small grains is the strong heating of the gas due to the photoelectric effect on grains near the ionization front. In this region, the Lyman continuum photons have been exhausted, and the only photons that are present are stellar and nebular photons below the Lyman limit (including the Ly $\alpha$ radiation) which are not absorbed by hydrogen, but can heat the gas via the photoelectric effect from dust grains. This results in an enhancement of the $[\mathrm{O} \mathrm{I}] \lambda 6300$ line, as seen in Tables 3 and 4. 

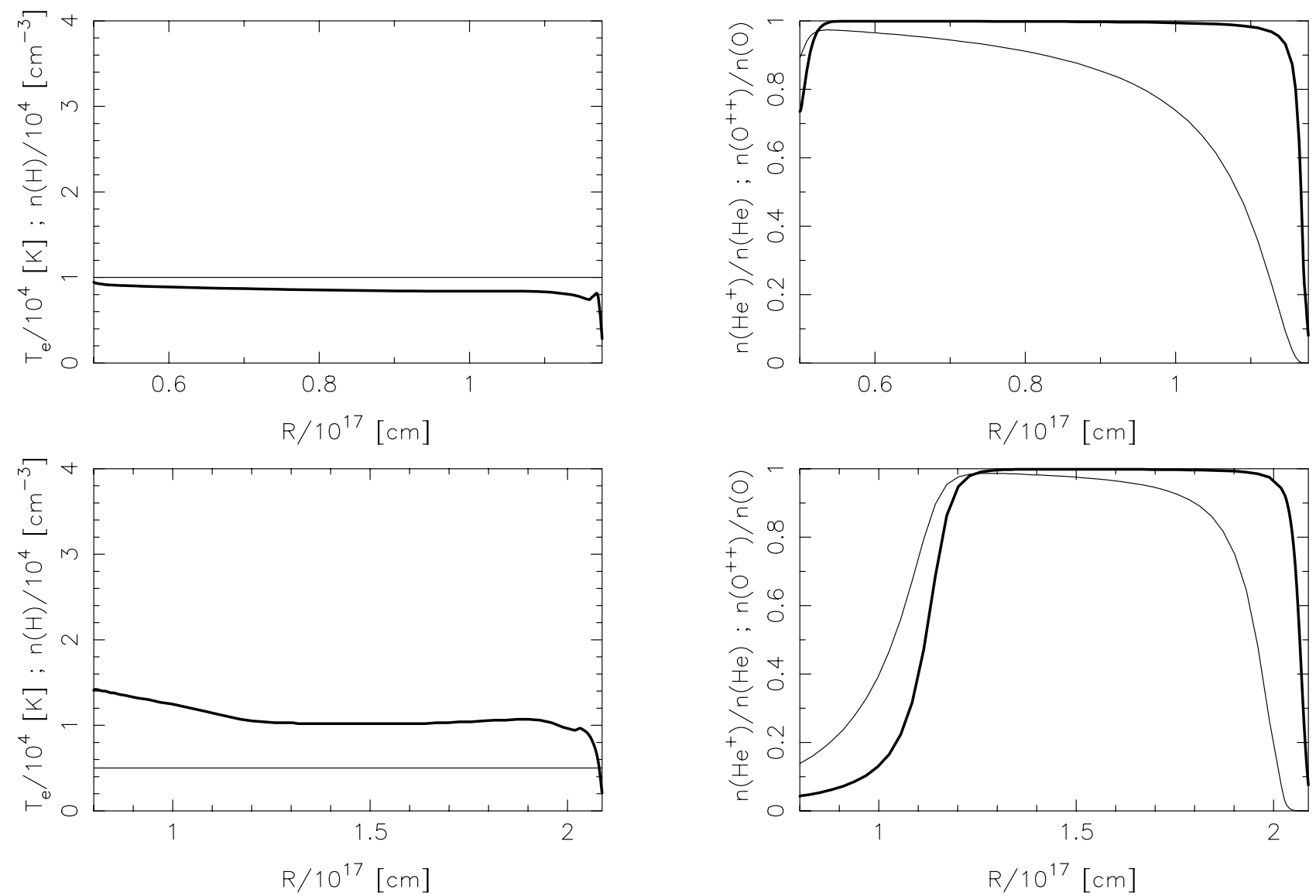

Fig. 2. The temperature and ionization structure of the same constant density models as in Fig. 1 but containing graphite grains with the MRN size distribution between 0.01 and $0.25 \mu \mathrm{m}$ and a dust-to-hydrogen mass ratio of $10^{-2}$ (Models Ba and $\mathrm{Bb})$. The presentation is the same as for the models shown in Fig. 1.

The heating efficiency of the small dust grains is such that even if present in a very small amount, they can affect the gas thermal balance significantly. We have run models $\mathrm{Da}$ and $\mathrm{Db}$ which are identical to models $\mathrm{Ca}$ and $\mathrm{Cb}$ except that the dust-to-hydrogen mass ratio of each grain population is $5 \times 10^{-4}$ instead of $5 \times 10^{-3}$. Table 3 shows that, in the $T_{*}=5 \times 10^{4} \mathrm{~K}$ models, such a small amont of dust increases the [O III $\lambda 4363 / 5007$ ratio from $3.31 \times 10^{-3}$ (dust free case) to $5.31 \times 10^{-3}$ and the electron temperature $T_{0}\left(\mathrm{O}^{++}\right)$from 8200 to $9200 \mathrm{~K}$. Such a difference is quite significant if one is interested in an accurate model fitting of a nebula. When comparing the models with $T_{*}=10^{5} \mathrm{~K}$ in Table 4 (models $\mathrm{Ab}$ and $\mathrm{Db}$ ), the results are less spectacular: the increase in $T_{0}\left(\mathrm{O}^{++}\right)$is only by $500 \mathrm{~K}$. This is because the photoelectric heating contribution is important in the inner regions, where oxygen is in the form of $\mathrm{O}^{+++}$and not of $\mathrm{O}^{++}$. The effect of dust heating is better seen on lines of more charged ions, such as $\mathrm{C}$ IV $\lambda 1550$ whose intensity with respect to $\mathrm{H} \beta$ (not shown in Table 4) is increased by a factor 2 .

One way to measure a temperature gradient in a nebula is to compare $T_{0}\left(\mathrm{O}^{++}\right)$and $T_{0}\left(\mathrm{O}^{+}\right)$. We see from Tables 3 and 4 that models with small grains increase the $T_{0}\left(\mathrm{O}^{++}\right) / T_{0}\left(\mathrm{O}^{+}\right)$ratio. As a matter of fact, as already stated by Dopita \& Sutherland (2000), dust could help explaining the observed temperature gradients in planetary nebulae. Indeed, the ratio $T_{\mathrm{r}[\mathrm{OIII}]} / T_{\mathrm{r}[\mathrm{NII}]}$ takes values between 1 and 1.5 in the planetary nebulae sample of Kingsburgh \& Barlow (1994). Such gradients are very difficult to produce with dust-free photoionization models. The most natural cause to investigate is density gradients, since the temperature is expected to be higher in regions of higher density, due to collisional deexcitation of the cooling lines. Figure 5 displays such models (Ea and $\mathrm{Eb}$ ), in which the density at given distance $R$ from the star is given by:

$n(\mathrm{H})=n(\mathrm{H})_{\text {in }} \exp \left\{-\left(\frac{R-R_{\text {in }}}{h}\right)^{2}\right\}$

where $R_{\text {in }}$ is the inner radius of the nebula and $h$ the thickness scale of the envelope chosen to be $5 \times 10^{16} \mathrm{~cm}$ for $T_{*}=5 \times 10^{4} \mathrm{~K}$ and $10^{17} \mathrm{~cm}$ for $T_{*}=10^{5} \mathrm{~K}$, respectively. These models have roughly the same outer radius and $\mathrm{H} \beta$ luminosity as models Aa and Ab. Our computed models show that the effect of such a density gradient is far from sufficient to produce an appreciable temperature gradient. Of course, one can think of much steeper density gradients, but in order to model a given object, the gradient should be compatible with the observed surface brightness distribution and the density derived from 

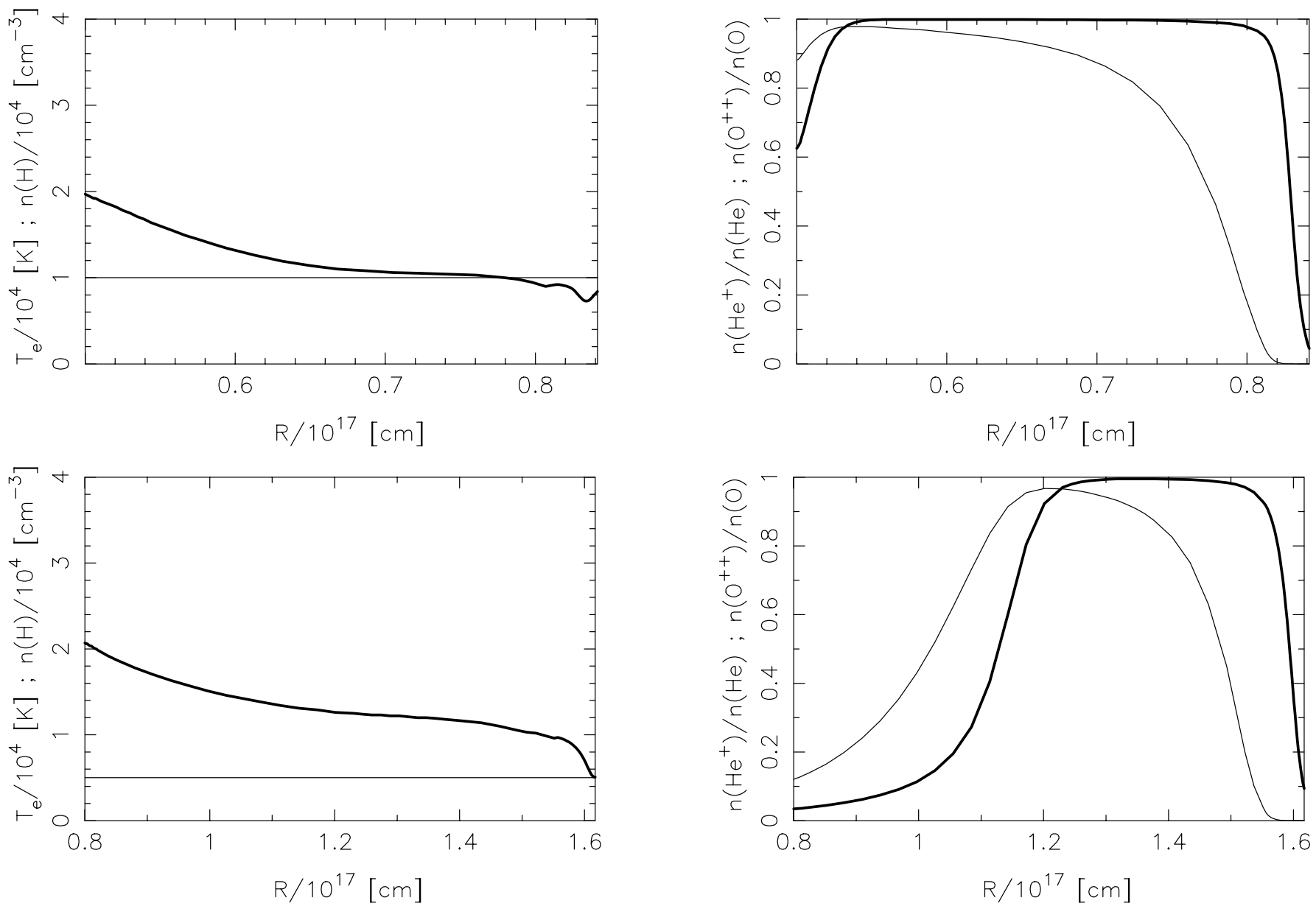

Fig. 3. The temperature and ionization structure of the same constant density models as in Fig. 2 but in which there are two populations of grains: small grains and large grains, each population having a dust-to-hydrogen mass ratio of $5 \times 10^{-3}$ (Models $\mathrm{Ca}$ and $\mathrm{Cb}$ ). The presentation is the same as for the models shown in Fig. 1.

[S II] $\lambda 6731 / 6717$ and $[\mathrm{Ar}$ IV] $\lambda 4741 / 4713$. Our experience is that it is generally very difficult to reproduce the observed temperature gradient with a density gradient compatible with the observations. Another possibility is to invoke depletion or chemical abundance gradients. But then it is the outer parts of the nebulae which should be richer in heavy elements, which makes such an assumption rather unlikely. The hypothesis of photoelectric heating by small dust grains provides a natural explanation to the outwards decrease of electron temperatures that is inferred from the observations. Of course, given all the unknowns as to the nature and physical properties of such grains, a detailed model fitting including small dust grains obviously would bear important uncertainties.

\section{The effect of dust on the temperature profiles of planetary nebulae with filamentary structures}

As mentioned in the introduction, density condensations have been proposed to explain the temperature fluctuations inferred from the differences between the temperatures derived from various indicators. But in order to significantly enhance the temperature derived from [O III] $\lambda 4363 / 5007$, very high densities $\left(\sim 10^{6} \mathrm{~cm}^{-3}\right)$ are required. Such densities are excluded by observations (e.g. Liu et al. 2001a). Modest density fluctuations, though, are obviously present, as seen on numerous high resolution images of planetary nebulae which reveal knots and filaments. In a dust-free nebula, the filaments will have a lowered ionization compared to the ambient gas, but the temperature will not be largely different from that of the ambient medium. We have modeled such a situation by assuming that the filaments are concentric shells and that the density distribution in the nebula is given by:

$n(\mathrm{H})=n(\mathrm{H})_{\min }+\delta n(\mathrm{H})\left(\cos \frac{2 \pi R}{\delta r}\right)^{2 q}$,

where $q$ is taken equal to 15 in order to produce filaments that occupy a small volume of the nebula.

Figure 6 shows such filamentary model nebulae (models $\mathrm{Fa}$ and $\mathrm{Fb}$ ) whose density distribution has been chosen to provide the same $\mathrm{H} \beta$ luminosity and size as models Aa and $\mathrm{Ab}$, with a density contrast $\delta n(\mathrm{H})$ of a factor 5 . Note that such completely ionized filaments are far from pressure equilibrium with the ambient gas, so their lifetime 

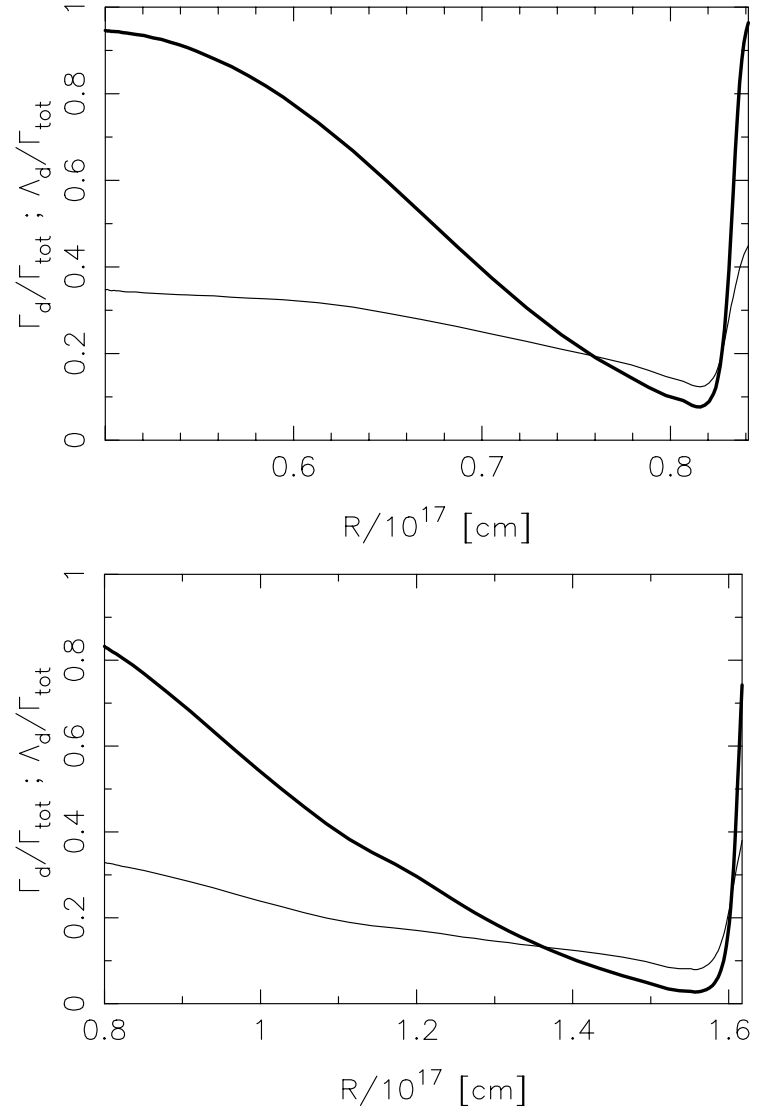

Fig. 4. The contribution of the heating due to the photoelectric effect from dust grains with respect to the total heating (thick line) and the proportion of cooling by grain-gas collisions with respect to the total cooling (thin line) as a function of the distance to the central star for the models shown in Fig. 3 (Models $\mathrm{Ca}$ - top and $\mathrm{Cb}$ - bottom).

is very short (about 30 years for filaments of thickness $10^{15} \mathrm{~cm}$ ) which means that they continuously form and disappear during the lifetime of the planetary nebula. If however the gas contains a population of small dust grains, the temperature inside the filaments is expected to be smaller than that of the ambient gas, since the importance of gas heating due to the photoelectric effect is roughly proportional to the ionization parameter, as stated above. Therefore, a decrease of $U$ in the denser regions will result in smaller heating due to the photoelectrons from dust grains. Figure 7 illustrates such a case, by showing models $\mathrm{Ga}$ and $\mathrm{Gb}$, which have the same input values as models $\mathrm{Fa}$ and $\mathrm{Fb}$ except that they contain dust with the same characteristics as models $\mathrm{Ca}$ and $\mathrm{Cb}$, respectively (i.e. small and large grains, each population with a dust-to-hydrogen mass ratio of $\left.5 \times 10^{-3}\right)$. Of course, the $\mathrm{H} \beta$ luminosity and the size of the ionized region is smaller than in models $\mathrm{Fa}$ and $\mathrm{Fb}$, due to the fact that dust grains compete with hydrogen to absorb the $\mathrm{H}$ Lyman continuum photons. We clearly see the predicted effect: the temperature inside the filaments is lower than in the ambient medium. The magnitude of the difference decreases with the distance to the ionizing star. Note that in such a model, the pressure discontinuities at the borders of the filaments are much smaller than in a dust-free model. In other words, filaments in a nebula containing small grains can survive longer than in a dust-free nebula.

\section{The effect of dust on the emission line analysis of planetary nebulae}

It is instructive to analyze our models with techniques used for the interpretation of the spectra of real planetary nebulae. The virtue of such "numerical observations" is that they eliminate the uncertainties in the atomic data, since they can be done using exactly the same atomic data as used in the computations of the models. Such an approach has been applied in different contexts by Gruenwald \& Viegas (1998) and Perinotto et al. (1998). Here we use our code ABELION to analyze the models computed with PHOTO with the same atomic data.

\subsection{Plasma diagnostics and abundance determinations from integrated spectra}

We have used the usual procedure of deriving $T_{\mathrm{r}[\mathrm{OIII}]}$ from $[\mathrm{O}$ III $] \lambda 4363 / 5007, T_{\mathrm{r}[\mathrm{N} \mathrm{II}]}$ from $[\mathrm{N} \mathrm{II}] \lambda 5755 / 6584$, $n_{\mathrm{e}[\mathrm{SII}]}$ from [S II] $\lambda 6731 / 6717$ and $n_{\mathrm{e}[\mathrm{ArIV}]}$ from [Ar IV] $\lambda 4741 / 4713$ ratio. The emissivities of hydrogen and helium ions as well as those of doubly ionized species of $\mathrm{C}, \mathrm{N}, \mathrm{O}$ and Ne were computed using $T_{\mathrm{r}[\mathrm{O} \text { III }]}$ and $n_{\mathrm{e}[\mathrm{Ar} I \mathrm{~V}]}$ while those of singly ionized species of $\mathrm{C}$, $\mathrm{N}, \mathrm{O}$ and Ne were computed using $T_{\mathrm{r}[\mathrm{NII}]}$ and $n_{\mathrm{e}[\mathrm{SII}]}$. The atomic abundance ratios were then derived from the ionic abundance ratios using the ionization correction factors of Kingsburgh \& Barlow (1994). The abundance of $\mathrm{O}$ was obtained using the value of $\mathrm{O}^{++} / \mathrm{H}^{+}$as derived from $\left[\mathrm{O}_{\mathrm{III}}\right] \lambda 5007 / \mathrm{H} \beta$. The $\mathrm{C} / \mathrm{O}, \mathrm{N} / \mathrm{O}$ and $\mathrm{Ne} / \mathrm{O}$ ratios were derived from the $\mathrm{C}$ III $] \lambda 1909 /[\mathrm{O}$ III $] \lambda 5007$, [N II] $\lambda 6584 /[\mathrm{O}$ II $] \lambda 3727$ and [Ne III] $\lambda 3869 /[\mathrm{O}$ III $] \lambda 5007$, respectively. The results are displayed in Tables 5 and 6 , respectively. For oxygen, we also show the determinations of $\mathrm{O}^{++} / \mathrm{H}^{+}$based on the other lines produced by $\mathrm{O}^{++}$(including the recombination line O III $\lambda 4651$ ) but still using $\left.T_{\mathrm{r}[\mathrm{OIII}]}\right)$. Since these lines have different dependences on the electron temperature (and density), differences between these various determinations of the $\mathrm{O}^{++}$abundance in the same model from integrated "numerical spectra" are a good measure of the temperature variations in the models (a somewhat similar approach was adopted by Mathis et al. 1998) in the discussion of observational data on planetary nebulae.

Inspection of Tables 5 and 6 reveals that the only cases where the computed $\mathrm{O} / \mathrm{H}$ is significantly different from the input value are models $\mathrm{Ca}, \mathrm{Fa}$ and $\mathrm{Ga}^{1}$. In the constant density case with small grains (model $\mathrm{Ca}$ ), $\mathrm{O} / \mathrm{H}$ is

\footnotetext{
${ }^{1}$ One does not expect the $\mathrm{O} / \mathrm{H}$ determinations to be exactly equal to the input values, since the temperature characteristic of the emission of the $\mathrm{H} \beta$ line is not equal to $T_{\mathrm{r}[\mathrm{OIII}]}$ and the correction for "unseen" oxygen ions introduces a slight error.
} 

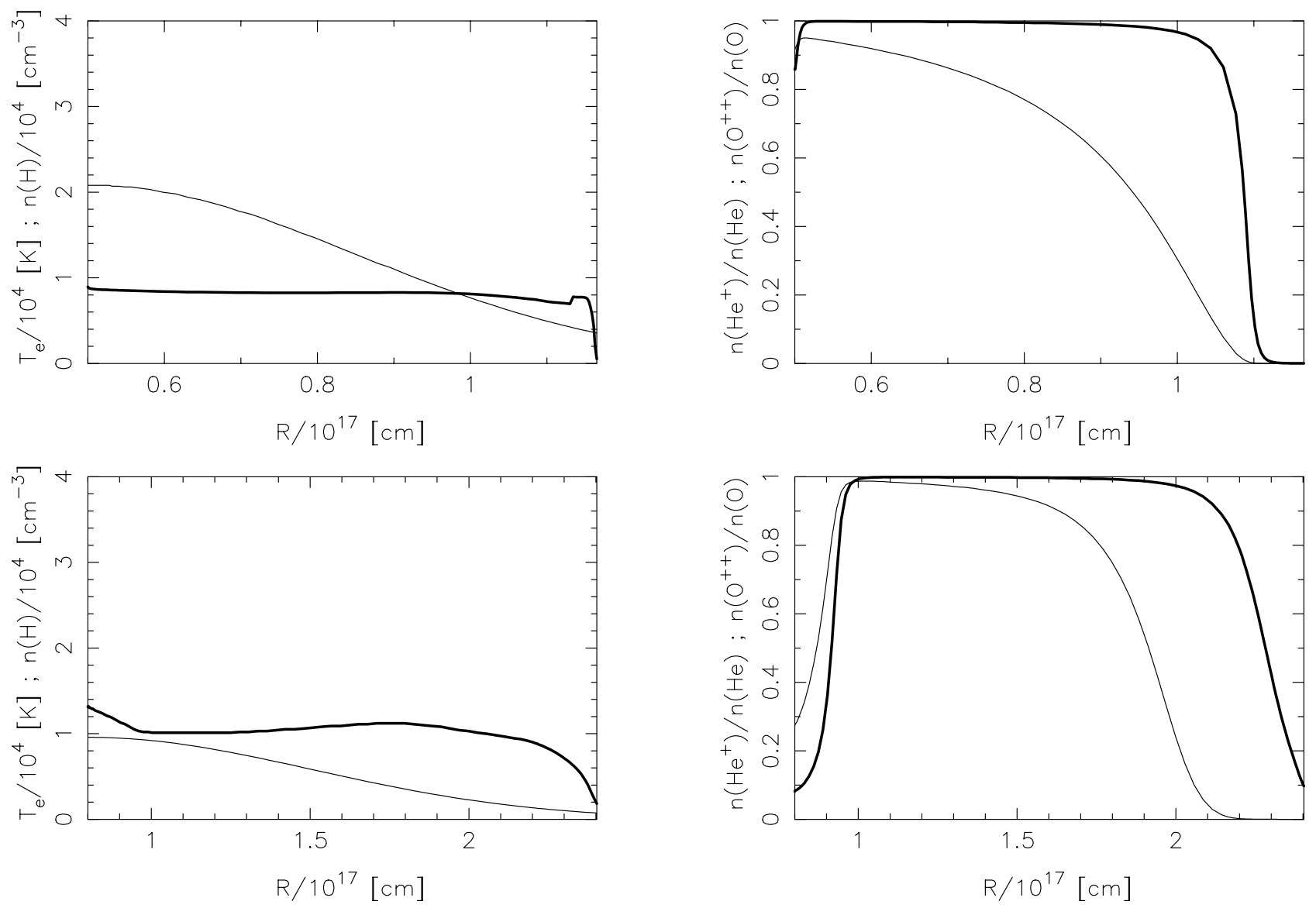

Fig. 5. The temperature and ionization structure of dust-free models with a density gradient, models Ea and Eb (see text). The presentation is the same as for the models shown in Fig. 1.

underestimated by about $40 \%$, because of the strong temperature gradient due to photoelectric heating by dust. In the dust-free case with filaments (case $\mathrm{Fa}$ ), $\mathrm{O} / \mathrm{H}$ is underestimated by $30 \%$, mainly because the determination of the $\mathrm{O}^{+}$abundance is biased by the presence of clumps of density higher than the critical density for the [O II] $\lambda 3727$ line. The case where the difference between the derived $\mathrm{O} / \mathrm{H}$ and the true one is the largest (almost a factor 2) is in model Ga, where small grains are present in a clumpy medium. Then, the temperature inhomogeneities are quite large and produce a significant bias in the oxygen abundance determination. That the effect is mainly due to temperature inhomogeneities can be seen from the fact that $\mathrm{O}^{++}(\lambda 1663) / \mathrm{O}^{++}(\lambda 5007)$ is 1.21 and $\mathrm{O}^{++}(\lambda 4651) / \mathrm{O}^{++}(\lambda 5007)$ is 1.40 , whereas these ratios are 0.985 and 1.05 , respectively, for the filamentary dust-free case. Note that in this model, the Balmer jump temperature (obtained by calibrating our theoretical Balmer jump index on isothermal photoionization models) is $10800 \mathrm{~K}$, significantly smaller than the temperature derived from [O III $\lambda 4363 / 5007$ and $[\mathrm{N} \mathrm{II}] \lambda 5755 / 6584$. As regards the models with $T_{*}=10^{5} \mathrm{~K}$, although qualitatively the effect of dust heating is similar to the one occuring in the models with $T_{*}=5 \times 10^{4} \mathrm{~K}$ (see Figs. 3 and 7 ), the error in the derived $\mathrm{O} / \mathrm{H}$ is much smaller. The reason is that photoelectric heating is strongest in the region populated by
$\mathrm{O}^{+++}$ions, while the classical oxygen abundance determination relies on lines emitted in the $\mathrm{O}^{++}$and $\mathrm{O}^{+}$zones. For the model which is most affected by temperature inhomogeneities (the filamentary model with dust, i.e. model $\mathrm{Gb}$ ), the Balmer jump temperature is $11500 \mathrm{~K}$. This is significantly lower than $T_{\mathrm{r}[\mathrm{O} \text { III }]}$ and than $T_{0}\left(\mathrm{H}^{+}\right)$, as can be seen in Tables 6 and 4 . For such a nebula, the effect of dust heating would have dramatic consequences on the interpretation of ultraviolet lines from higher ionization species, such as $\mathrm{C}^{+++}, \mathrm{N}^{+++}$and $\mathrm{O}^{+++}$.

\subsection{Interpretation of spatially resolved observations}

We have also computed the electron temperatures, densities and abundances for simulated observations on lines of sight located at different projected distances from the central star. The temperature profiles $T_{\mathrm{r}[\mathrm{O} I \mathrm{II}]}$ and $T_{\mathrm{r}[\mathrm{N} \mathrm{II}]}$ are shown in Fig. 8 for our dust-free homogeneous models $(\mathrm{Aa}$ and $\mathrm{Ab})$ and for the homogeneous models with small grains $(\mathrm{Ca}$ and $\mathrm{Cb})$. We see that dusty models containing a population of small particles (our models $\mathrm{Ca}$ and $\mathrm{Cb}$ ) do show a significant gradient in $T_{\mathrm{r}[\mathrm{O} I \mathrm{II}]}$ in contrast with dust-free models (Aa and $\mathrm{Ab})$. For example $T_{\mathrm{r}[\mathrm{O} I \mathrm{II}]}$ varies from $14200 \mathrm{~K}$ (in the center) to $10500 \mathrm{~K}$ (in the outskirts) in model Ca, and from $13500 \mathrm{~K}$ (in the center) to $8500 \mathrm{~K}$ (in the outskirts) in model $\mathrm{Cb}$, while in dust-free models 

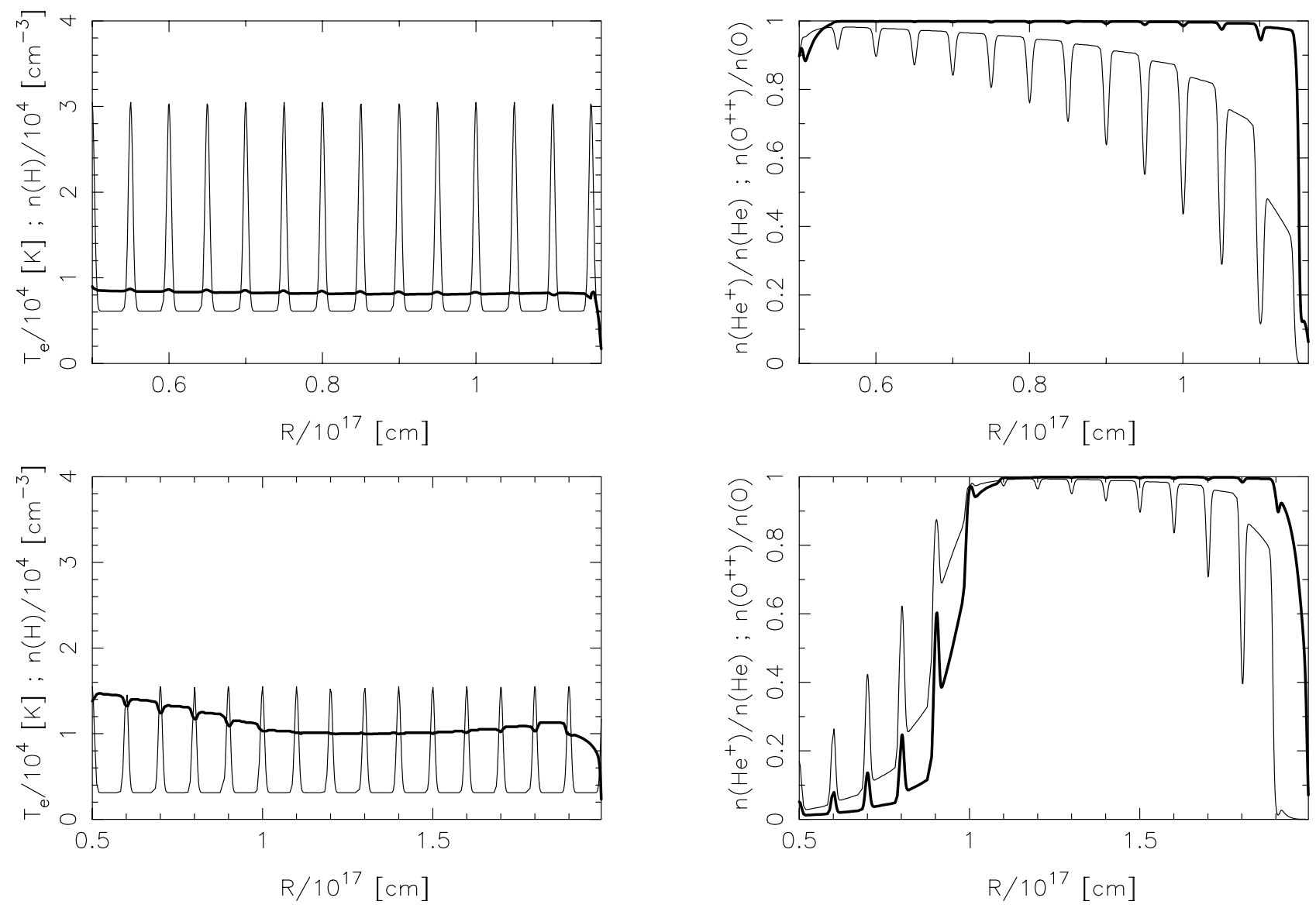

Fig. 6. The temperature and ionization structure of the dust-free filamentary models $\mathrm{Fa}$ and $\mathrm{Fb}$, which have the same total $\mathrm{H} \beta$ flux as models Aa and Ab (see text). Same presentation as in Fig. 1.

the $T_{\mathrm{r}[\mathrm{O} I I I]}$ variations are of the order of $500 \mathrm{~K}$ only. The variation of $T_{\mathrm{r}[\mathrm{NII}]}$ across the face of the nebulae is very mild (a few hundred K only), even in the case of dusty models, which is not surprising since these lines arise in the outer parts of the nebulae.

\section{The temperature fluctuation parameter}

Numerous studies have used the temperature fluctuation concept introduced by Peimbert (1967) and derived $t^{2}$ from observational data (although as pointed out for example by Kingdon \& Ferland 1995 the value derived from the observations does not strictly correspond to the definition of $t^{2}$ ). Besides, as demonstrated by Stasińska (2001) on two-zone toy models, different temperature distributions with formally the same value of $t^{2}$ and same mean temperature can give very different ratios of the various lines emitted by $\mathrm{O}^{++}$.

Because of this long tradition in the use of $t^{2}$, it is worth commenting on the values of $t^{2}$ found in our models (they correspond to the $t_{\mathrm{str}}^{2}$ values of Kingdon \& Ferland 1995). As seen in Tables 3 and 4 , and as noted by previous authors, the values of $t^{2}\left(\mathrm{H}^{+}\right), t^{2}\left(\mathrm{O}^{+}\right)$and $t^{2}\left(\mathrm{O}^{++}\right)$may actually be quite different. They are smaller than $10^{-2}$ for all our models except those containing small dust grains with a dust-to-hydrogen mass ratio $5 \times 10^{-3}$. Models with only one population of grains with the MRN size distribution between 0.01 and $0.25 \mu \mathrm{m}$ and a dust-to-hydrogen mass ratio of $10^{-2}$ (Models $\mathrm{Ba}$ and $\mathrm{Bb}$ ) do give higher values of $t^{2}$ than the analogous dust-free counterparts, but they are still of the order of a few $10^{-3}$ or less. In this case, actually, higher values of $t^{2}$ result from a temperature gradient rather than a small scale temperature variation. The dust-free models with inhomogeneous density distributions return values of $t^{2}$ that are similar to constant density models.

On the other hand, models containing small grains return values of $t^{2}$ largely above $10^{-2}$. In the constant density cases, this is due to the strong temperature gradients in the inner zone, which induce a $t^{2}\left(\mathrm{H}^{+}\right)$of the order of $3-4 \times 10^{-2}$. For $\mathrm{O}^{+}$, the value of $t^{2}$ is smaller (but still around $10^{-2}$ ) because this zone is distant from the star and less affected by photoelectric heating. A similar remark holds for $t^{2}\left(\mathrm{O}^{++}\right)$in the $T_{*}=10^{5} \mathrm{~K}$ model.

In the filamentary models with small grains (models $\mathrm{Ga}$ and $\mathrm{Gb})$, The values of $t^{2}\left(\mathrm{H}^{+}\right)$and $t^{2}\left(\mathrm{O}^{++}\right)$are further increased with respect to the constant density models, because of the important small-scale temperature variation seen in Fig. 7. This is the first time that photoionization models give such large values of $t^{2}$ for nebulae with solar vicinity chemical composition and moderate effective temperatures. 

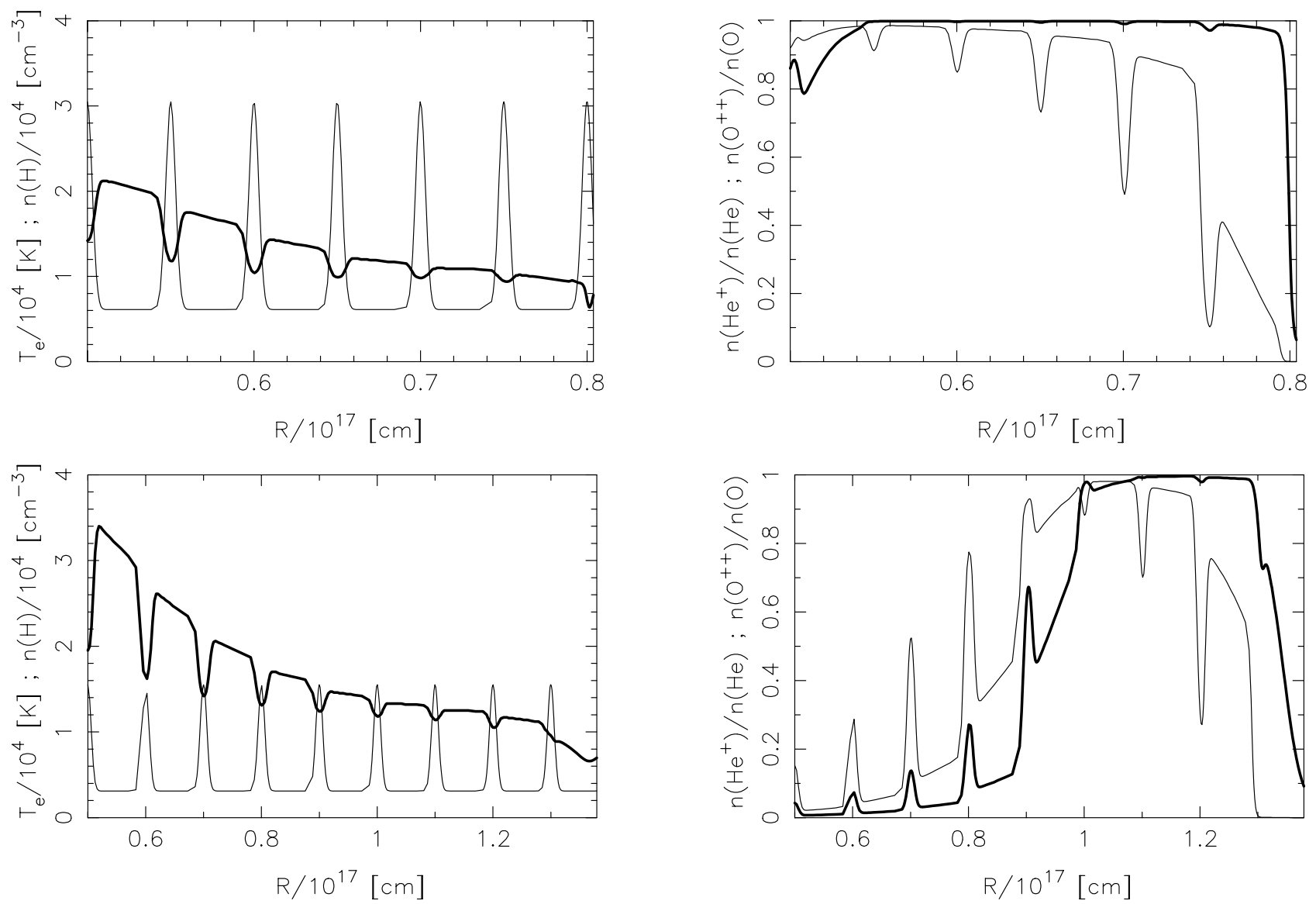

Fig. 7. The temperature and ionization structure of filamentary models (Ga and Gb) with similar input parameters as models $\mathrm{Fa}$ and $\mathrm{Fb}$ except that they contain dust with the same characteristics as models $\mathrm{Ca}$ and $\mathrm{Cb}$. Same presentation as in Fig. 1.

\section{Concluding remarks}

In continuation of previous studies on the effects of dust grains in ionized plasmas (e.g. Spitzer 1948; Baldwin et al. 1991; Weingartner \& Draine 2001b), we have investigated the role of dust in the thermal balance of planetary nebulae. This subject has been introduced by the works of Borkowski \& Harrington (1991) and Dopita \& Sutherland (2000), the first one studying the particular case of a hydrogen-poor dust heated planetary nebula, the second one exploring more generally the conditions under which dust heating plays a role in planetary nebulae. These last authors found that dust heating is important if a population of small dust grains is assumed.

In the present study, we have analyzed in more detail the consequences of the presence of such grains in planetary nebulae, by considering several typical examples. In short, we have constructed photoionization models for two families of nebulae. One concerns rather dense nebulae $\left(n(\mathrm{H})=10^{4} \mathrm{~cm}^{-3}\right)$ surrounding relatively cool central stars $\left(T_{*}=5 \times 10^{4} \mathrm{~K}\right)$. The other concerns more diluted nebulae $\left(n(\mathrm{H})=5 \times 10^{3} \mathrm{~cm}^{-3}\right)$ surrounding hot central stars $\left(T_{*}=10^{5} \mathrm{~K}\right)$. Such cases provide good examples of different situations encountered in planetary nebulae. We have studied the temperature profiles of such models for different dust contents and different density distributions. As expected, the effect of dust heating is particularly important in the presence of a population of small grains. The electron temperature increases by a factor of about 2 in the central regions when adopting a population of small grains with a dust-to-hydrogen mass ratio of $5 \times 10^{-3}$. Observational consequences of such a temperature increase are seen in optical spectra only if the high temperature zone contains a large proportion of $\mathrm{O}^{++}$ions which provide good temperature diagnostics.

The presence of small grains in planetary nebulae can explain a number of problems that have found no solution so far. For example, tailored photoionization models of individual planetary nebulae sometimes indicate an energy deficit in the thermal balance: the electron temperature derived from the observation of [O III] $\lambda 4363 / 5007$ is higher than can be obtained by photoionization models. This is the case in two of the five planetary nebulae with Wolf-Rayet central stars studied by Peña et al. (1998).

Also, high signal-to-noise, spatially resolved observations of several planetary nebulae show that the temperatures derived from [O III $] \lambda 4363 / 5007$ smoothly decrease with projected distance to the central star. Indirect indications of such gradients are provided by ratios $T_{\mathrm{r}[\mathrm{O} \text { III }]} / T_{\mathrm{r}[\mathrm{NII}]}$ larger than one in spatially resolved observations as well as in integrated spectra of many planetary nebulae. Such gradients are difficult to reproduce with 
Table 5. Abundances determination for models with $T_{*}=5 \times 10^{4} \mathrm{~K}$.

\begin{tabular}{|c|c|c|c|c|c|c|c|}
\hline & model Aa & model $\mathrm{Ba}$ & model $\mathrm{Ca}$ & model Da & model Ea & model Fa & model Ga \\
\hline$T_{\mathrm{r}[\mathrm{O} \mathrm{III}]}$ & 8242. & 8552. & 13504. & 9356. & 8330. & 8422. & 13145. \\
\hline$T_{\mathrm{r}[\mathrm{NII}]}$ & 8197. & 8434. & 10480. & 9079. & 8776. & 9051. & 11334. \\
\hline$n_{\mathrm{e}[\mathrm{S} \mathrm{II}]}$ & 9120. & 8837. & 6832. & 7444. & 6548. & 14782. & 10108. \\
\hline$n_{\mathrm{e}[\mathrm{Ar} I \mathrm{IV}]}$ & 11120 . & 11091. & 10949. & 11012. & 20401. & 13830. & 12338. \\
\hline $\mathrm{He}^{+}(\lambda 5876) / \mathrm{H}^{+}$ & $1.11 \mathrm{E}-01$ & $1.13 \mathrm{E}-01$ & $1.07 \mathrm{E}-01$ & $1.14 \mathrm{E}-01$ & $1.12 \mathrm{E}-01$ & $1.12 \mathrm{E}-01$ & $1.08 \mathrm{E}-01$ \\
\hline $\mathrm{He}^{++}(\lambda 4686) / \mathrm{H}^{+}$ & $1.34 \mathrm{E}-04$ & $1.88 \mathrm{E}-04$ & 7.36E-04 & 2.03E-04 & $1.37 \mathrm{E}-04$ & $1.35 \mathrm{E}-04$ & $6.18 \mathrm{E}-04$ \\
\hline $\mathrm{He} / \mathrm{H}$ & $1.12 \mathrm{E}-01$ & $1.14 \mathrm{E}-01$ & $1.08 \mathrm{E}-01$ & $1.15 \mathrm{E}-01$ & $1.12 \mathrm{E}-01$ & $1.12 \mathrm{E}-01$ & $1.08 \mathrm{E}-01$ \\
\hline $\mathrm{O}^{+}(\lambda 3727) / \mathrm{H}^{+}$ & $1.20 \mathrm{E}-04$ & $1.12 \mathrm{E}-04$ & $7.04 \mathrm{E}-05$ & $8.23 \mathrm{E}-05$ & $6.34 \mathrm{E}-05$ & $8.83 \mathrm{E}-05$ & $5.55 \mathrm{E}-05$ \\
\hline $\mathrm{O}^{++}(\lambda 5007) / \mathrm{H}^{+}$ & $3.26 \mathrm{E}-04$ & $3.30 \mathrm{E}-04$ & $2.61 \mathrm{E}-04$ & $3.32 \mathrm{E}-04$ & $3.57 \mathrm{E}-04$ & $2.77 \mathrm{E}-04$ & $2.18 \mathrm{E}-04$ \\
\hline $\mathrm{O}^{++}(\lambda 1663) / \mathrm{H}^{+}$ & $3.37 \mathrm{E}-04$ & $3.42 \mathrm{E}-04$ & $3.08 \mathrm{E}-04$ & $3.56 \mathrm{E}-04$ & $3.71 \mathrm{E}-04$ & $2.73 \mathrm{E}-04$ & 2.63E-04 \\
\hline $\mathrm{O}^{++}(\lambda 52 \mu \mathrm{m}) / \mathrm{H}^{+}$ & $3.27 \mathrm{E}-04$ & $3.31 \mathrm{E}-04$ & $3.08 \mathrm{E}-04$ & $3.43 \mathrm{E}-04$ & $4.04 \mathrm{E}-04$ & $2.66 \mathrm{E}-04$ & $2.25 \mathrm{E}-04$ \\
\hline $\mathrm{O}^{++}(\lambda 88 \mu \mathrm{m}) / \mathrm{H}^{+}$ & $3.26 \mathrm{E}-04$ & $3.30 \mathrm{E}-04$ & $3.05 \mathrm{E}-04$ & $3.42 \mathrm{E}-04$ & $4.17 \mathrm{E}-04$ & $2.83 \mathrm{E}-04$ & $2.35 \mathrm{E}-04$ \\
\hline $\mathrm{O}^{++}(\lambda 4651) / \mathrm{H}^{+}$ & $3.28 \mathrm{E}-04$ & $3.33 \mathrm{E}-04$ & $3.48 \mathrm{E}-04$ & $3.53 \mathrm{E}-04$ & $3.56 \mathrm{E}-04$ & $2.92 \mathrm{E}-04$ & $3.06 \mathrm{E}-04$ \\
\hline $\mathrm{O} / \mathrm{H}$ & $4.47 \mathrm{E}-04$ & 4.43E-04 & $3.32 \mathrm{E}-04$ & $4.15 \mathrm{E}-04$ & $4.21 \mathrm{E}-04$ & $3.66 \mathrm{E}-04$ & $2.75 \mathrm{E}-04$ \\
\hline $\mathrm{C} / \mathrm{O}$ & $1.29 \mathrm{E}+00$ & $1.28 \mathrm{E}+00$ & $1.17 \mathrm{E}+00$ & $1.23 \mathrm{E}+00$ & $1.28 \mathrm{E}+00$ & $1.31 \mathrm{E}+00$ & $1.19 \mathrm{E}+00$ \\
\hline $\mathrm{N} / \mathrm{O}$ & $4.14 \mathrm{E}-01$ & $4.20 \mathrm{E}-01$ & $5.21 \mathrm{E}-01$ & $4.70 \mathrm{E}-01$ & $5.23 \mathrm{E}-01$ & $5.67 \mathrm{E}-01$ & $6.86 \mathrm{E}-01$ \\
\hline $\mathrm{Ne} / \mathrm{O}$ & $2.62 \mathrm{E}-01$ & $2.65 \mathrm{E}-01$ & $2.73 \mathrm{E}-01$ & $2.68 \mathrm{E}-01$ & $2.59 \mathrm{E}-01$ & $2.71 \mathrm{E}-01$ & $2.83 \mathrm{E}-01$ \\
\hline
\end{tabular}

Table 6. Abundances determination for models with $T_{*}=10^{5} \mathrm{~K}$.

\begin{tabular}{|c|c|c|c|c|c|c|c|}
\hline & model Ab & model $\mathrm{Bb}$ & model $\mathrm{Cb}$ & model $\mathrm{Db}$ & model Eb & model $\mathrm{Fb}$ & model Gb \\
\hline$T_{\mathrm{r}[\mathrm{OIII}]}$ & 10388. & 10588. & 12968. & 10974. & 10597. & 10472. & 13067. \\
\hline$T_{\mathrm{r}[\mathrm{N} \mathrm{II}]}$ & 10303. & 10247. & 10770. & 10500. & 10988. & 11159. & 11494. \\
\hline$n_{\mathrm{e}[\mathrm{S} \mathrm{II}]}$ & 3947. & 3964. & 4105. & 3975 . & 2180. & 5439. & 6171. \\
\hline$n_{\mathrm{e}[\mathrm{ArIV}]}$ & 5649. & 5650. & 5706. & 5645. & 8916. & 8935. & 9394. \\
\hline $\mathrm{He}^{+}(\lambda 5876) / \mathrm{H}^{+}$ & $1.07 \mathrm{E}-01$ & $1.05 \mathrm{E}-01$ & $8.67 \mathrm{E}-02$ & $1.05 \mathrm{E}-01$ & $1.05 \mathrm{E}-01$ & $1.08 \mathrm{E}-01$ & $8.58 \mathrm{E}-02$ \\
\hline $\mathrm{He}^{++}(\lambda 4686) / \mathrm{H}^{+}$ & 8.73E-03 & $1.10 \mathrm{E}-02$ & $2.69 \mathrm{E}-02$ & $1.13 \mathrm{E}-02$ & $9.09 \mathrm{E}-03$ & $8.96 \mathrm{E}-03$ & $2.82 \mathrm{E}-02$ \\
\hline $\mathrm{He} / \mathrm{H}$ & $1.16 \mathrm{E}-01$ & $1.16 \mathrm{E}-01$ & $1.14 \mathrm{E}-01$ & $1.16 \mathrm{E}-01$ & $1.14 \mathrm{E}-01$ & $1.17 \mathrm{E}-01$ & $1.14 \mathrm{E}-01$ \\
\hline $\mathrm{O}^{+}(\lambda 3727) / \mathrm{H}^{+}$ & $5.70 \mathrm{E}-05$ & $6.13 \mathrm{E}-05$ & $7.34 \mathrm{E}-05$ & $6.02 \mathrm{E}-05$ & $3.09 \mathrm{E}-05$ & $4.55 \mathrm{E}-05$ & $6.20 \mathrm{E}-05$ \\
\hline $\mathrm{O}^{++}(\lambda 5007) / \mathrm{H}^{+}$ & $3.79 \mathrm{E}-04$ & $3.64 \mathrm{E}-04$ & $2.86 \mathrm{E}-04$ & $3.65 \mathrm{E}-04$ & $4.08 \mathrm{E}-04$ & $3.51 \mathrm{E}-04$ & $2.61 \mathrm{E}-04$ \\
\hline $\mathrm{O}^{++}(\lambda 1663) / \mathrm{H}^{+}$ & $3.93 \mathrm{E}-04$ & $3.79 \mathrm{E}-04$ & $3.08 \mathrm{E}-04$ & $3.79 \mathrm{E}-04$ & $4.25 \mathrm{E}-04$ & $3.60 \mathrm{E}-04$ & $2.83 \mathrm{E}-04$ \\
\hline $\mathrm{O}^{++}(\lambda 52 \mu \mathrm{m}) / \mathrm{H}^{+}$ & $3.89 \mathrm{E}-04$ & $3.76 \mathrm{E}-04$ & $3.08 \mathrm{E}-04$ & $3.77 \mathrm{E}-04$ & $4.84 \mathrm{E}-04$ & $3.76 \mathrm{E}-04$ & $3.01 \mathrm{E}-04$ \\
\hline $\mathrm{O}^{++}(\lambda 88 \mu \mathrm{m}) / \mathrm{H}^{+}$ & $3.91 \mathrm{E}-04$ & $3.77 \mathrm{E}-04$ & $3.09 \mathrm{E}-04$ & $3.78 \mathrm{E}-04$ & $5.33 \mathrm{E}-04$ & $4.33 \mathrm{E}-04$ & $3.52 \mathrm{E}-04$ \\
\hline $\mathrm{O}^{++}(\lambda 4651) / \mathrm{H}^{+}$ & $3.89 \mathrm{E}-04$ & $3.76 \mathrm{E}-04$ & $3.16 \mathrm{E}-04$ & $3.77 \mathrm{E}-04$ & $4.18 \mathrm{E}-04$ & $3.67 \mathrm{E}-04$ & $2.94 \mathrm{E}-04$ \\
\hline $\mathrm{O} / \mathrm{H}$ & $4.59 \mathrm{E}-04$ & $4.55 \mathrm{E}-04$ & $4.30 \mathrm{E}-04$ & $4.56 \mathrm{E}-04$ & $4.64 \mathrm{E}-04$ & $4.18 \mathrm{E}-04$ & $3.91 \mathrm{E}-04$ \\
\hline $\mathrm{C} / \mathrm{O}$ & $1.04 \mathrm{E}+00$ & $1.02 \mathrm{E}+00$ & $9.93 \mathrm{E}-01$ & $1.00 \mathrm{E}+00$ & $1.03 \mathrm{E}+00$ & $1.06 \mathrm{E}+00$ & $9.97 \mathrm{E}-01$ \\
\hline $\mathrm{N} / \mathrm{O}$ & $5.88 \mathrm{E}-01$ & $5.80 \mathrm{E}-01$ & $5.82 \mathrm{E}-01$ & $5.87 \mathrm{E}-01$ & $6.26 \mathrm{E}-01$ & $8.12 \mathrm{E}-01$ & $7.55 \mathrm{E}-01$ \\
\hline $\mathrm{Ne} / \mathrm{O}$ & $3.01 \mathrm{E}-01$ & $3.04 \mathrm{E}-01$ & $3.15 \mathrm{E}-01$ & $3.03 \mathrm{E}-01$ & $2.85 \mathrm{E}-01$ & $3.17 \mathrm{E}-01$ & $3.29 \mathrm{E}-01$ \\
\hline
\end{tabular}

photoionization models, even considering density gradients. They are naturally explained if one assumes that the nebulae contain small grains.

Also, photoelectric heating by small dust grains naturally explains, at least qualitatively, why in planetary nebulae Balmer jump temperatures are smaller than the temperatures derived from [O III] $\lambda 4363 / 5007$.

Detailed photoionization modelling of planetary nebulae often predicts too small a value of the $[\mathrm{O} \mathrm{I}] \lambda 6300$ intensity as compared to observations (Clegg et al. 1987; de Marco \& Crowther 1999; Dudziak et al. 2000). 

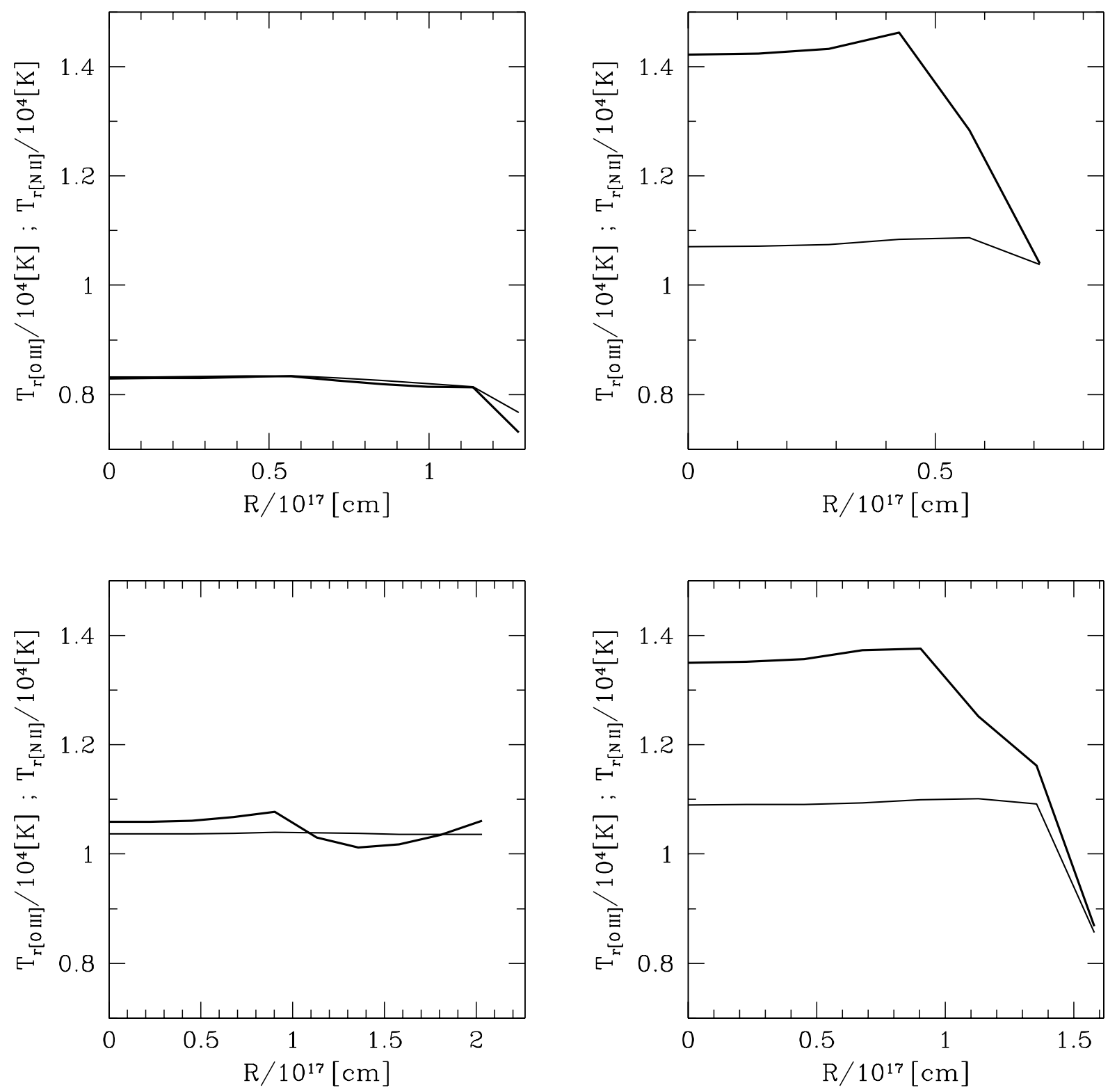

Fig. 8. $T_{\mathrm{r}[\mathrm{O} I \mathrm{II}]}$ (thick lines) and $T_{\mathrm{r}[\mathrm{NII}]}$ (thin lines) at different projected distances from the central star for constant density dust-free models (Aa and Ab, left panels) and for constant density models with two populations of grains: small grains and large grains, each population having a dust-to-hydrogen mass ratio of $5 \times 10^{-3}$ (Models Ca and Cb, right panels). As in the other figures, upper panels correspond to $T_{*}=5 \times 10^{4} \mathrm{~K}$ and lower panels to $T_{*}=10^{5} \mathrm{~K}$.

One way to enhance this line in dust free plasmas is by assuming high density optically thick condensations, which will strongly reduce the local ionization parameter and boost the $[\mathrm{O}$ I $] 26300$ lines with respect to smooth density models. However, [O I] $\lambda 6300$ can also be enhanced by additional heating in the transition zone between ionized and neutral gas. This heating can be provided by the photoelectric effect on small dust grains, whose importance with respect to heating by photoionization increases as the Lyman continuum photons become exhausted.

Moderate density inhomogeneities, such as are inferred from the distribution of the surface brightness of many planetary nebulae, produce only minimal spatial temperature variations in dust-free nebulae. The presence of small dust grains completely modifies the small scale temperature structure of filamentary planetary nebulae, by spectacularly boosting the temperature of the diluted component. This results in a situation closer to pressure equilibrium between filament and ambient gas than in absence of small grains.

It is perhaps by measuring directly the temperature in and between filaments that one would have the best indirect indication of the presence of small grains in planetary nebulae.

Such observations would be really worthwhile, since our models show that small dust grains inside planetary nebulae are able to provide a natural solution to the long standing problem of temperature fluctuations first mentioned by Peimbert (1967). 
There is still a huge amount of work to be done on dust properties before photoelectric heating can be modelled to the same degree of reliability as other heating processes in ionized nebulae. Impressive progress in this sense has been made recently (Weingartner \& Draine 2001a; Li \& Draine 2001; Draine \& Li 2001; Weingartner \& Draine 2001b) but many uncertainties remain.

We have shown that small dust grains are a promising explanation for a number of problems encountered in planetary nebulae. Still, several problems will not be solved. These are: i) the large inverse temperature gradients materialized by the small $T_{\mathrm{r}[\mathrm{O} \text { III }]} / T_{\mathrm{r}[\mathrm{N} \mathrm{II}]}$ ratios observed in some planetary nebulae (Peña et al. 2001); ii) the very low Balmer jump temperatures (around $3.5 \times 10^{3} \mathrm{~K}$ ) observed in a few planetary nebulae (Liu et al. 2001a); iii) the origin of the large discrepancies between abundances derived from forbidden and collisionally excited lines of the same ions. Concerning the latter item however, Liu et al. (2000) make the point that present computations of the effective recombination coefficients for line emission do not take into account dielectronic recombinations for states with principal quantum number above 10 . These processes are expected to strongly enhance the emissivities of the recombination lines at temperatures above $2 \times 10^{4} \mathrm{~K}$. Since small grains are able to boost the electron temperature to such high values in the most tenuous parts of filamentary or knotty planetary nebula, they might well also solve the recombination line conundrum, if the speculation about the enhancement of the recombination line emissivities at high temperatures proves to be true.

Acknowledgements. This work was supported by the Jumelage France-Pologne, by the Polonium program (contract No. 03242XJ) and the grant 2.P03D.020.17 from the Polish Committee for Scientific Research. R.Sz. is grateful for the hospitality of the DAEC in Paris-Meudon Observatory and G.S. for the hospitality of NCAC in Toruń.

\section{References}

Aitken, D. K., Roche, P. F., \& Spenser, P. M. 1979, ApJ, 233, 925

Aller, L. H., \& Czyzak, S. J. 1983, ApJS, 51, 211

Baldwin, J. A., Ferland, G. J., Martin, P. G., et al. 1991, ApJ, 374,580

Barlow, M. J. 1983, in Planetary Nebulae, ed. D. R. Flower (D. Reidel Publishing Company), IAU Symp., 103, 105

Barlow, M. J. 1993, in Planetary Nebulae, ed. R. Weinberger, \& A. Acker (Kluwer Academic Publishers), IAU Symp., 155,163

Binette, L., Wang, J., Villar-Martin, M., et al. 1993, ApJ, 414, 535

Borkowski, K. J., \& Harrington, J. P. 1991, ApJ, 379, 168

Clegg, R. E. S., Harrington, J. P., Barlow, M. J., \& Walsh, J. R. 1987, MNRAS, 314, 551

Cohen, M., Barlow, M. J., Sylvester, R. J., et al. 1999, ApJ, 513, L135

de Marco, O., \& Crowther, P. A. 1999, MNRAS, 306, 931
Draine, B. T., \& Laor, A. 1993, ApJ, 402, 441

Draine, B. T., \& Li, A. 2001, ApJ, 551, 807

Dopita, M. A., \& Sutherland, R. S. 2000, ApJ, 539, 742

Dudziak, G., Péquignot, D., Zijlstra, A. A., \& Walsh, J. R. 2000, A\&A, 363, 717

Esteban, C. 2001, Rev. Mex. Astron. Astrofis., Conf. Ser., in press

Garnett, D. R., \& Dinerstein, H. L. 2001, ApJ, 558, 145

Gȩsicki, K., Acker, A., \& Szczerba, R. 1996, A\&A, 309, 907

Gillett, F. C., Forrest, W. J., \& Merrill, K. M. 1973, ApJ, 183, 87

Gruenwald, R., \& Viegas, S. M. 1998, ApJ, 501, 221

Harrington, J. P., Monk, D. J., \& Clegg, R. E. S. 1988, MNRAS, 231, 577

Kingdon, J. B., \& Ferland, G. J. 1995, ApJ, 450, 691

Kingsburgh, R. L., \& Barlow, M. J. 1994, MNRAS, 271, 257

Li, A., \& Draine, B. T. 2001, ApJ, 550, 213

Liu, X.-W., \& Danziger, I. J. 1993, MNRAS, 263, 256

Liu, X.-W., Barlow, M. J., Cohen, M., et al. 2001a, MNRAS, 323,343

Liu, X.-W., Luo, S.-G., Barlow, M. J., et al. 2001b, MNRAS, in press

Liu, X.-W., Storey, P. J., Barlow, M. J., et al. 2000, MNRAS, 312,585

Lenzuni, P., Natta, A., \& Panagia, N. 1989, ApJ, 345, 306

Mathis, J. S., Rumpl, W., \& Nordsieck, K. H. 1977, ApJ, 217, 425

Mathis, J. S., Torres-Peimbert, S., \& Peimbert, M. 1998, ApJ, 495, 328

Natta, A., \& Panagia, N. 1981, ApJ, 248, 189

Peimbert, M. 1967, ApJ, 150, 825

Peña, M., Stasińska, G., Esteban, C., et al. 1998, A\&A, 337, 866

Peña, M., Stasińska, G., \& Medina, S. 2001, A\&A, 367, 983

Péquignot, D., \& Stasińska, G. 1980, A\&A, 81, 121

Perinotto, M., Kifonidis, K., Schönberner, R., \& Marten, H. 1998, A\&A, 332, 1044

Pottasch, S. R. 1984, Planetary Nebulae (D. Reidel Publishing Company)

Roche, P. F. 1989, in Planetary Nebulae, ed. S. TorresPeimbert (Kluwer, Dordrecht), IAU Symp., 131, 117

Shields, G. A. 1978, ApJ, 219, 559

Shields, G. A. 1983, in Planetary Nebulae, ed. D. R. Flower (D. Reidel Publishing Company), IAU Symp., 103, 259

Spitzer, L. Jr. 1948, ApJ, 107, 6

Stasińska, G. 2001, Rev. Mex. Astron. Astrofis., Conf. Ser., in press

Stasińska, G., \& Leitherer, C. 1996, ApJS, 107, 661

Stasińska, G., \& Szczerba, R. 1999, A\&A, 352, 297

Szczerba, R., Górny, S. K., Stasińska, G., et al. 2001, Ap\&SS, 275,113

Viegas, S. M., \& Clegg, R. E. S. 1994, MNRAS, 271, 993

Viegas, S. M., \& Contini, M. 1994, ApJ, 428, 113

Volk, K., Dinerstein, H., \& Sneden, C. 1997 in Planetary Nebulae, ed. H. J. Habing, \& J. G. L. M. Lamers (Kluwer Academic Publishers), IAU Symp., 180, 284

Waters, L. B. F. M., Beintema, D. A., Zijlstra, A. A., et al. 1998, A\&A, 331, L61

Weingartner, J. C., \& Draine, B. T. 2001a, ApJ, 548, 296

Weingartner, J. C., \& Draine, B. T. 2001b, ApJS, 134, 263 